\title{
External Intervention, Identity, and Civil War
}

\author{
Nicholas Sambanis \\ University of Pennsylvania \\ Department of Political Science \\ Stergios Skaperdas \\ University of California, Irvine \\ Department of Economics \\ William Wohlforth \\ Dartmouth College \\ Department of Government
}

May 17, 2017

\begin{abstract}
Scholarship on civil wars has focused on domestic causes, but recent research suggests that such causes are actually contingent on systemic conditions. We demonstrate this interaction concerning polarization. We provide statistical evidence for the importance of external intervention in conflict escalation. We then construct models in which external intervention is the catalyst for civil war in combination with other factors, focusing on ethnic or social identitification. In our model, local actors with a foreign patron are emboldened and pursue their objectives violently. Without the specter of intervention, polarization is not often sufficient to induce war. The model qualifies important empirical results that have established a direct, linear relationship between polarization and civil war and shows how it is possible to have war without asymmetric information or credible commitment problems. We present case examples consistent with our theoretical claim. The model serves as a bridge between international relations and comparative political-economy approaches to internal armed conflict.
\end{abstract}




\section{Introduction}

In his final news conference, President Barack Obama observed that in dealing with Russia he confronted "an approach to global affairs that seems to be premised on the idea that whatever America's trying to do must be bad for Russians," bringing back the "adversarial spirit that ... existed during the Cold War." ${ }^{1}$ For scholars of international politics, that calls forth visions of arms races, crises, and fears of major power war. In this paper, we address a potentially devastating implication of heightened systemic rivalry: its effect on inter-group conflicts within states. The Cold War was an inter-state setting in which governments and their domestic opponents both had reasons to believe that if they played they cards right-in particular if they could present their group identity in ways that might appeal to outside powers-they might well count on major external support for their internal struggle. And that pernicious interaction between international and domestic conflict helps account for much of the blood shed in regional conflicts during the Cold War (Westad 2006).

Accounts of these conflicts suggest that the systemic-domestic interaction was much more complex than simply a matter of big powers funneling arms into local conflicts and thereby prolonging them. Rather, the competitive global environment shaped how domestic groups within states framed their political and social identities in the first place and how they bargained with each other. In the lead up to Angola's civil war, for example, leaders of the competing factions formulated group identities in ways meant to link up with the global contestation between the United States and the Soviet Union (Guimarães 1998). A nonviolent bargain on transferring power after Portugal's exit was frustrated by the increased polarization between the contending parties and by the fact that expectations of external support "ensured that each of the rival groups believed they had a good chance to emerge victorious, thus reducing the desirability of peaceful negotiations" (Telepneva 2014 283).

Similar interactions characterized other so-called proxy wars during the Cold War from

\footnotetext{
${ }^{1}$ New York Times 2017 "Obama's Last News Conference: Full Transcript and Video" Jan 18th https://www.nytimes.com/2017/01/18/us/politics/obama-final-press-conference.html?_r=0
} 
Lebanon and Afghanistan to Nicaragua and Vietnam, but they are hardly unique to the mid 20th century. In nearly any period in the modern history of international politics when great powers were at odds, there was the potential for intervention to politicize and militarize intra-state (often intra-empire) cleavages. No one can understand 19th century geopolitics, for example, without such staples as the Irish Question (perennial fears in Whitehall that external powers might take a page from Napoleon's book and intervene on behalf of Irish independence), the Polish question (fears in Berlin, Vienna and especially St Petersburg concerning external support for Polish independence), the Great Game (fears in London that the encroachment of Russian power in Central Asia would catalyze fissiparous tendencies in British India) and perhaps most fatefully the Eastern Question (fears in Constantinople and the great European capitals that Russian support for fellow Slavs or Orthodox believers in the Balkans could topple the Ottoman Empire in Europe and facilitate the expansion of the Tsar's sway to the Black Sea straits). These dynamics may be becoming more prominent now as factors explaining separatism in places as disparate as Ukraine, the Democratic Republic of the Congo, Yemen, Somalia, or Syria.

These episodes reflect a complex interaction between inter-state competition and identity politics, featuring an external intervener, some subgroup within a rival state or its ally comprised of individuals inclined to identify locally or even feel some affinity for the intervening power. But the international dimensions of social identity and civil war are as obvious as they are understudied. The massive outpouring of scholarly research after the Cold War's end overwhelmingly sees civil war as a failure of the domestic political economy and focuses on domestic causes, such as poverty, repression, inequality or ethnic difference. Most quantitative studies of civil war look for direct, linear effects of these variables without considering the international system as an enabling factor for conflict. ${ }^{2}$ This is perhaps most evident in

\footnotetext{
${ }^{2} \mathrm{By}$ contrast, qualitative research has addressed the impact of foreign intervention and great power politics. Mylonas (2015), for example, explain how governments' decisions to assimilate or expel ethnic minorities depend on the nature of their relationship with foreign supporters of those groups. Some quantitative studies of conflict at the group level have considered indirect measures of the potential for external assistance, such as the availability of sanctuaries (Salehyan 2007) or cross-border ethnic kin groups (Cederman, Girardin, Gleditsch 2009) or the target state's involvement in an inter-state rivalry (Salehyan, Gleditsch, and Cun-
} 
studies of the effect of ethnic fragmentation or polarization on conflict onset. Ethnic fragmentation and polarization are typically measured using static indices that cannot explain the timing of war onset and cannot capture the changing salience of ethnicity, yet most studies still try to explain conflict outbreaks by comparing countries' ethnic makeup.

While scholars have made progress on understanding the effect of intervention on civil war duration and termination (discussed below), research on the role of intervention as a cause of war onset is in its infancy. In particular, the effect of intervention on war onset has not yet been explored in a theoretical framework that integrates insights from the literature on the domestic political economy of civil war. We fill this gap by providing a broad, flexible theory of how external intervention affects the risk of conflict escalation and civil war between two ethnic groups engaged in a contest over resources. We do so in a formal model that advances the extant literature in a number of ways. By capturing different instruments of intervention, distinguishing between war, rebellion, and settlement under the threat of war and by modeling the effect of identity differences, we are better able to understand the potential effects of hightened inter-state rivalry on what has been the main form of organized group violence for the past seven decades, intra-state war.

We begin by establishing what we know and don't know about the polarization of identities, intervention and civil war onset. We then present results from cross-country regressions that highlight the role of intervention in civil war onset-a relationship that has not yet been developed in the literature. This evidence provides the impetus for our new model of how intervention affects war onset. We model a conflict over autonomy or secession and show how intervention provides mechanisms through which conflict can escalate from rebellion to civil war. We distinguish between different types of conflict that can occur and show how intervention and social identification independently, but also in interaction, can induce conflict. The model is general enough to apply to non-ethnic or non-separatist conflicts. We modify the model to consider cases in which rebels seek to overthrow the central government (we ningham 2011; see also Toukan 2017 for a more general theory of how inter-state rivalries affect civil war dynamics in neighboring states). 
present a summary of the differences from the autonomy model and relegate the modeling details to a supplement available online). Next, we emphasize that intervention does not only affect the bargaining calculations of the parties - it also affects their identities. We extend the model to endogenize ethnic identification and group polarization to intervention. In other words, intervention catalyzes the effect of ethnic distance on conflict by generating polarization. The causal mechanisms of the model are traced in case histories of conflict escalation after the collapse of the USSR. We review the histories of 71 self-determination movements in the post-Soviet space and conduct an in-depth case analysis of the conflict in Ukraine. The cases provide confirmatory evidence for the model and the case of Ukraine's civil war highlights the role of intervention in making ethnic identities and polarization politically salient.

\section{Identity, Intervention and the Onset of War}

The dominant approach in the scholarly literature is to explain civil war as a failure of the domestic political economy and to test for correlations between war onset and structural characteristics of countries, such as the level of poverty, the extent of repression, or the presence of ethnic divisions in the population. Most empirical studies look for direct, linear effects of these variables and have not considered the international system as an enabling factor for conflict. This approach is perhaps most evident in studies of the effect of ethnic fragmentation or polarization on conflict onset. Ethnic fragmentation and polarization are measured using static indices that cannot explain the timing of war onset, yet many studies puzzle over why the ethno-linguistic fractionalization index is not a good predictor of war onset.

Fearon and Laitin (2003) published an early result showing no correlation between civil war and ethnic fractionalization and many subsequent quantitative studies have confirmed this. Yet a large historical and sociological literature on nationalism and violent rebellions argues that there is a link between ethnic difference, cultural antipathy, and conflict (e.g. 
Wimmer 2012; Hall and Malasevic 2014). This discrepancy is largely explained by the mismatch between theory and empirical proxies used in quantitative studies. The validity of empirical proxies of ethnic difference has been questioned, as static measures of countries' demographies cannot capture the depth of group divisions (Chandra and Wilkinson 2008). Faced with this criticism of the commonly used index of ethno-linguistic fractionalizationthe default measure of ethnic difference in most civil war models-a second wave of studies proposed different measures, which corrected for cultural distance between ethnic groups (Fearon 2003), selected only politically-relevant ethnic groups (Posner 2004), or replaced the fractionalization index with a measure of polarization (having a few large groups rather than many small ones). A strong result from the second wave of studies is that polarization is correlated positively with civil war (Montalvo and Reynal-Querrol 2005; Esteban, Mayoral, and Ray 2012). ${ }^{3}$

The relationship between ethnic polarization and civil war is now taken to be a robust empirical fact. Yet the theory of how polarization affects conflict is not properly tested in the empirical literature. Empirical measures of polarization cannot capture the complex ways in which politics affects ideological divisions or the changing salience of ethnic identities. Recent theoretical contributions to the study of ethnic conflict have shown that social identification is a dynamic, historically contingent process (Sambanis and Shayo 2013). People do not have fixed, single social identies but rather multiple identities, the relative salience of which can vary in response to social stimuli (Roccs and Brewer 2002). Violence exposure, status reversals, and inter-group competition all affect the salience of ethnic identification and the degree to which one group identity is framed in opposition to another. Although a large literature in social psychology has shown that ingroup bias is common, there is an emerging consensus that such bias or ethnic prejudice do not lead to violent ethnic conflict unless ethnic differences are combined with structural features of politics, such as inequality

\footnotetext{
${ }^{3}$ An alternative approach, discussed below, by Cederman, Min, and Wimmer (2010) and Wimmer (2012) is to focus on political exclusion of ethnic groups as a cause of conflict rather than simply measure the demographic size of groups.
} 
or exclusion from power (Cederman et al 2010; Wimmer 2012; 2002). Similarly, external shocks that lead to status reversals can generate ethnic fear and resentment among groups that might have remained at peace under different circumstances (Petersen 2001). We build on these insights to explore the role of external intervention as catalyst for conflict in ethnically polarized societies. By modeling the interaction between ethnic polarization and intervention, we highlight a new mechanism through which ethnic differences can be mobilized to produce violence and advance the formal analysis of the nexus between domestic conflict and international power politics.

Ours is not the first study of the effects of intervention on civil war. There is an extensive literature focusing on civil war duration and termination that has dealt extensively with intervention. Early empirical studies include Regan (2000), who found that wars with intervention (and counter-intervention) last longer than others; and Doyle and Sambanis (2000), who found that international peacekeeping intervention can help shore up the peace after war ends. Several other studies have replicated and extended these results. But the role of intervention as a cause of war onset is less well understood.

Scholars have considered more discrete questions, such as whether an impartial third party can intervene to improve the welfare of the country (Amegashie and Kutsoati, 2007); whether a third party can optimally intervene by reducing the marginal cost of military expenditures of one side (Chang et al, 2007); or whether alliance formations are stable when third party intervention is endogenous to conflict dynamics (Powell 2017). Some of these studies include models and Amegashie (2010) provides an overview of modeling issues in external interventions, emphasizing the determination of the intervener's objectives. In a related paper, he shows that anticipated intervention on behalf of the minority can lead the government to increase its investments in arms (Amegashie 2014; see also Poast 2015 for a relevant argument and a historical example). Grigoryan (2010) also considers adverse effects of intervention and models the conditions under which intervention on behalf of a minority can push the government to use more violence. The moral hazard of intervention 
has been the focus of recent formal (Rowlands and Carment 1998; Kydd and Straus 2013) and historical (Kuperman 2013) studies, but most studies do not fully consider that moral hazard arguments cut both ways and non-intervention can also embolden the state in its repression of challengers. An exception is Wagner (2005), who explains that credible promises of intervention should resolve uncertainty between conflicting groups, thereby reducing the risk of violent escalation. The problem, of course, is that promises of intervention are not always credible, so "expectations about possible interventions may play a role in motivating an internal conflict" (Wagner 2007, 229), consistent with the model that we develop later.

These arguments about the likely impact of intervention on domestic conflict have been developed mostly in the context of incomplete information environments and bargaining games. It has been shown that civil war can be prolonged as a result of uncertainty about the extent or likelihood of external intervention (Sawyer et al, 2015; Powell 2017); and that interventions that help establish power parity among domestic actors can make conflict outbreaks more likely as they create uncertainty over the confict outcome (Bas and Schub 2016). The expectation of intervention on the side of rebels could escalate conflicts as rebel demands get progressively more expansive (Jenne 2004); by making the government take preemptive action (Poast 2015); or otherwise create bargaining failures (Grigoryan 2010, Cetinyan 2003). What is missing from that literature is a focus on the interplay between intervention and other key determinants of conflict, such as social identification. While the effects of intervention on bargaining dynamics are better understood, the significance of foreign involvement in domestic armed conflicts is not limited to the creation of credible commitment problems. What is needed is a theoretical architecture that can explore how domestic actors' incentives can change as a result of foreign intervention and how their identities complicate that relationship. ${ }^{4}$

\footnotetext{
${ }^{4}$ Formal and quantitative studies, including the ones we cite earlier (e.g. Salehyan 2007; Salehyan et al 2011) do not focus on group identification as that is hard to measure. They take groups as given and consider how external support might affect group actions during civil war. By contrast, qualitative studies (e.g. Mylonas 2013) focus on the effect of the external security environment on the strength of ethnic identification and on state actions in response to perceptions about minorities' loyalties to neighboring states.
} 
A related approach emphasizing cultural difference and identities as a cause of violent conflict is Spolaore (2008), who explains secessionist wars in a model in which groups can pursue secession to avoid paying "heterogeneity costs" due to ethnic distance from the rest of the nation. In his model, ideological closeness or ethnic affinity are traded off to the cost of providing public goods. We incorporate this insight in our model and ask how intervention affects conflict escalation in the presence of such heterogeneity costs. We also incorporate the idea that conflict generates contingent spoils so that local actors receive subsidies from third parties contingent on fighting. This can generate war in a rationalist framework without information or commitment problems. ${ }^{5}$

Specifically, we model the interaction between a government and a group that may seek autonomy, secession, or to overthrow the government. The government represents the interests of a dominant group and the group out of power first has the choice between acquiescing to the status quo or rebelling. Rebellion can lead to either a negotiated settlement or civil war. That is, there are three sets of outcomes that are possible: the status quo, rebellion followed by settlement, and rebellion followed by civil war. This allows for a more nuanced and empirically accurate discussion of civil wars, which typically grow out of gradually escalating conflicts. Civil war, in turn, leads to either victory or defeat of the rebels. This setting allows for a rich set of factors that could lead to rebellion and civil war that involve both external intervention and identity issues. Intervention can take different forms: unrestricted subsidies conditional on rebellion; restricted subsidies to military efforts; training, organization, and equipment purchases for the rebels or the government; commitments for future economic support of a region that secedes or a group that takes over the government. These different instruments of external intervention can induce rebellion and civil war, but identity also matters. The perceived ethnic or other distance between the two groups and

\footnotetext{
${ }^{5}$ A similar insight can be found in Monteiro and Debs (2017), where war creates efficiency gains that are not attainable during peacetime; and Powell (2013), where the spoils of war are contingent on monopolizing violence; though in Powell's model, even a peace agreement that results in an asymmetrical distribution of power can create these spoils so war is not necessary. The key insight can also be found in the debate on relative gains in international relations theory (Grieco 1988; Snidal 1991).
} 
their relative size can induce rebellion and civil war, but intervention interacts with identity and ethnic polarization, which is a function of both perceived cultural-ideological distance and the relative size of the groups. ${ }^{6}$ None of the factors that lead to rebellion or civil war require the presence of commitment problems or asymmetric information, the two set of factors usually considered necessary for the onset of conflict. But before we present this model in detail, we need to address a prior question: is there any evidence that intervention can explain why conflicts escalate to civil war?

\section{Preliminary Evidence on the Relevance of External Intervention on War Onset}

Does external intervention increase the prevalence of civil war? Patrick Regan's (2000) pioneering work on the subject established the connection between intervention and longer war durations. Regan considered mainly biased interventions and found that they prolong war duration particularly when there are competing interventions on behalf of both rebels and the government. A complementary empirical result concerns the effects of impartial peacekeeping interventions, which are designed to keep parties from returning to war after an initial settlement is reached. Doyle and Sambanis (2000) showed that such interventions by the United Nations help shore up the peace after civil war and several studies have replicated and reinforced that result. But what is the effect of intervention on initial war onset?

Most available data sources do not allow an analysis of the effect of intervention on war onset as the typical approach has been to code interventions only in ongoing conflicts. This data constraint is severely limiting, but we can probe the relationship between intervention and war onset in two ways. First, we consider whether adding a proxy for intervention to a well-known model of civil war can change the model's results. The (exogenous) proxy

\footnotetext{
${ }^{6}$ It follows that other determinants of ethnic distance will also affect conflict risk indirectly. For example, the risk of separatist conflict is higher among groups with previous experience in autonomous government or groups who live in areas far from the capital (Wimmer and Min 2006). Such groups are less likely to consider themselves part of the nation.
} 
variable is the Cold War. We add it to a standard civil war model and explore if it interacts with the effect of key variables in ways that the extant literature has not appreciated. We focus on how the Cold War interacts with the effect of ethnic polarization. Our theory would suggest that polarization is more likely to raise the risk of civil war if domestic groups receive (or are promised) external assistance to challenge the government. Thus we test whether adding Cold War changes the relationship between ethnic polarization and civil war risk. Previous studies show a very robust relationship, yet we find that the effect of polarization is in fact conditional on the international environment. Specifically, ethnic polarization only increases the risk of civil war during the Cold War, when there were many more competing interventions and the expectation of a biased intervention was much higher than in the postCold War period (until recently, as we discuss in the case-study section). This evidence is not conclusive, but it is consistent with our expectations. Second, we compile existing data on third-party troop deployments in active minor conflicts and explore whether such interventions can explain why some minor armed conflicts turn into civil wars. This analysis is limited to country-years with active conflicts and we show that intervention does have a significant escalatory effect on conflict. That effect is robust to controlling for country fixed effects as well as several variables that might affect countries' conflict proneness. Together, these empirical results motivate the theoretical model that we develop later.

\subsection{The Effect of the Cold War on Conflict}

A striking result in a large quantitative literature on civil war is that countries with higher ethno-linguistic fractionalization indices (ELF) do not have a higher risk of war onset. Scholars have interrepeted this counter-intuitive result liberally to infer that ethnic difference and nationalism are not contributing factors for insurgency and civil war (Fearon and Laitin 2003). One of the first studies to challenge such interpretations was Montalvo and ReynalQuerol (2005), who obtained a statistically significant correlation between war and ethnic difference simply by substituting or supplementing the ethnic fractionalization index with 
an index measuring ethnic polarization. Like the fractionalization index, their polarization index was constructed using static measures of group sizes without actually controlling for perceived ethnic distance or ideological differences between the groups. The advance over ELF was that they could capture different ethnic structures: high values of their polarization index characterize countries with a small number of large groups as opposed to high values in the fractionalization index, which characterize countries with many small groups. A simple model of civil war regressed on the standard controls plus the ethnic polarization index yields a strong positive correlation (see Table 1, column 1). What is missing, however, is an explanation for the mechanism underlying ethnic polarization and war. Recent theoretical contributions by Esteban and Ray (2011) do provide a mechanism linking polarization to conflict, but the mechanism is one that focuses exclusively on the domestic political economy and there is no distinction in the model between actual conflict and settlement under the threat of conflict. ${ }^{7}$ We provide a different approach, arguing that external conditions might in fact determine when ethnic polarization is associated with conflict, while also distinguishing between different types of conflict.

Data on interventions are not available for countries without ongoing conflicts so to probe the plausibility of our argument we use an indirect approach. We extend the model proposed by Montalvo and Reynal-Querol (2005) to test whether the effect of polarization is conditional on the international environment and, specifically, on conditions that favor external intervention (the Cold War). We take advantage of the fact that there is a sufficient number of wars in Montalvo and Reynal-Querol's data both before and after the end of the Cold War and look for differences in the effects of the polarization variable in the two periods. Any such difference would be instructive, since expectations of partial external intervention were radically different in the two periods. The Cold War was characterized by superpower competition as the world was divided in spheres of influence and proxy wars in the periphery were common. Regional hegemons coordinated their actions with their superpower sponsors

\footnotetext{
${ }^{7}$ Conflict in their model is also not explicitly political as there is no government in the model.
} 
resulting in many interventions in civil wars by neighboring countries. If the effect of ethnic polarization on conflict is different in the Cold War period relative to the post-Cold War period, then this would be consistent with our claim that patterns of external intervention could "activate" latent ethnic cleavages that might otherwise lay dormant.

To test this claim, we re-estimate Montalvo and Reynal-Querol's model, adding an indicator variable for the Cold War (coldwar). Their data is organized in country five-year periods and the Cold War variable is coded 1 for the first 6 five-year periods and 0 for the last 2 periods. There are 274 observations with 57 periods of war in the post-Cold War period and 822 observations with 102 periods of war in the Cold War period. The Cold War variable is weakly significant and negative (Table 1, column 2) and the results of the baseline model do not change significantly. The dependent variable is coded 1 in each country-five-year period with a civil war according to the PRIO/UCDP dataset. ${ }^{8}$ Next, in column 3, we add an interaction between the ethnic polarization index and the Cold War indicator $\left(C W^{*} P\right)$. We find that the linear polarization term is no longer significant; the positive association between ethnic polarization and civil war is only statistically significant during the Cold War period. The same is not true for ethnic fractionalization, which is consistently non-significant throughout these regressions whether independently or in interaction with the Cold War indicator (column 4, Table 1). We obtain similar results if we use a different version of the dependent variable, coded by Fearon and Laitin (see results in our online supplement, which includes additional robustness tests). In the supplement, we show similar results when we replicate a study by Esteban, Mayoral, and Ray (2012), which uses a measure of ethnic polarization in a different model of civil war.

The data by Montalvo and Reynal-Querol end in 2000. We updated their dataset to include wars until 2015 and improved the quality of the data used to code explanatory variables in a number of ways outlined in our supplement. These updates reduce the number

\footnotetext{
${ }^{8}$ This is the preferred measure of war in Montalvo and Reynal-Querol (2005). They report that their analysis of war onset produces similar results, though they have many fewer observations of war in that instance.
} 
of missing observations and give us many more post-Cold War periods of war. We now have 102 country five-year periods of war since the Cold War ended and 93 periods during the Cold War. Results are reported in column 5 of Table 1 and we again see a similar pattern with polarization being statistically significant in the Cold War period alone. Using improved data for several of the explanatory variables, we can now obtain significant results for per capital income, population, and resource-dependence. As a further robustness test, we use a differently coded polarization measure based on the Ethnic Power Relations (EPR) dataset (Cederman, Wimmer and Min 2010). That measure yields very different polarization values for some countries (the correlation with the original measure is just .55) since it codes all politically-relevant ethnic cleavages in each country (e.g. tribe or race) rather than only linguistic groups. Our results (reported in the supplement) become stronger with the new measure of ethnic polarization.

\section{Insert Table 1 here}

\subsection{Intervention and Escalation from Minor Conflicts}

Next, we take a more direct approach to probe the relationship between intervention and civil war. We use country-year data to explore the connection between intervention and conflict escalation. This approach has limitations as intervention is by necessity treated as exogenous in the escalation models we present in this section. Domestic imperatives and interests in the intervening country likely influence decisions to intervene (or not), yet it is unlikely that intervention is entirely exogenous to conflict dynamics in the target country. Thus, the causal effect of intervention cannot be identified in these cross-country regressions. Nonetheless, the results are useful as they complement the preceding analysis, which has already established a link between conflict and an indirect and plausibly exogenous measure of intervention (the Cold War). By modeling intervention directly, we can now delve deeper to show that a robust correlation exists between patterns of intervention and conflict escalation. The correlations presented are illuminating as to our knowledge this is the first time a relationship between 
intervention and conflict escalation has been shown using cross-country data. ${ }^{9}$

As mentioned earlier, data on intervention in countries without active conflicts do not exist. Thus, it is not possible to study whether intervention or its anticipation generates conflict in the first place. We can, however, study the effect of intervention on conflict escalation if we drop all observations with no active conflict and focus on cases of minor armed conflict where a minimum of 25 battle-deaths are registered in a given year. By restricting the sample this way, we can then test whether intervention is a statistically significant predictor of escalation from minor conflict to full-blown civil war. ${ }^{10}$ Our data source for minor conflicts is the UCDP dataset. Our source of civil war data is Sambanis (2004), with coverage extended to 2012. Conflicts that eventually accumulate 1,000 deaths and meet other criteria (e.g. reciprocal violence and continuous violent activity) are coded as civil wars. Conflicts that do not meet those criteria remain coded as minor incidents. Using these data, we can test whether intervention can explain why some conflicts escalate to civil war. Out of 296 conflict onsets in the UCDP data, 171 cases correspond to civil war onsets in our data; out of these 94 correspond to conflicts that started out as minor and escalated to war. ${ }^{11}$ Using the UCDP classification of conflicts into ethnic and non-ethnic, we can test the effect of intervention on ethnic conflicts separately. This is consistent with the model we develop later, which differentiates between claims for secession/autonomy -which are usually ethnic in nature - and other conflicts over control of the central government.

Data on interventions also come from the UCDP database, which defines interventions

\footnotetext{
${ }^{9}$ A related approach is Schulhofer-Wohl (2016) who studies the effect of intervention on conflict duration and violence intensity in civil war including among "on-side" (i.e. allied) groups. He shows that intervention can lead to ritualistic fighting that is not aimed at winning; rather, fighting serves to destabilize the government to benefit external sponsors and it lasts as long as domestic groups receive subsidies. It follows that escalation or de-escalation can result from changes in the level of subsidies from foreign sponsors.

${ }^{10}$ This approach also suggests that we do not believe that intervention is a necessary condition for conflict outbreak. Domestic factions can overcome organizational hurdles in others ways to rebel. Yet it is possible that the anticipation of external assistance emboldens groups to start small conflicts that will later only become large if intervention materializes.

${ }^{11}$ All except 22 civil war onsets occur during periods when the UCDP dataset codes an ongoing conflict. The 22 cases of coding disagreement are dropped since we only want to analyze periods of ongoing minor conflict. We also identify a number of ambiguous cases of civil war, where one or more of the coding criteria in Sambanis (2004) might not be satisfied and drop those cases to check robustness.
} 
narrowly to include only troop deployments by third parties. These actions represent a subset of the ways in which a third party may affect the interaction between the government and domestic challengers in the model that we develop later. However, the UCDP data offer a good starting point for a baseline analysis. The data also allow us to distinguish between pro-government and pro-rebel interventions. We expect the effects of intervention on civil war risk to be different depending on the target. Given the power asymmetry between government and rebels, it is reasonable to expect that pro-government intervention will reduce the risk of conflict escalation. Cunningham (2016) offers supportive evidence for this claim, showing that countries with significant military-political support from the United States are less likely to experience violent challenges. By contrast, intervention on behalf of rebel organizations or small ethnic groups challenging the state should increase the risk of civil war by increasing the capabilities of those groups (Elbadawi and Sambanis 2000).

Results are presented in Table 2 below. We use logistic regression, clustering standard errors at the country level throughout with the exception of models 3 and 4 , where we also include country fixed effects to capture unobserved sources of country heterogeneity. The first two columns include only the intervention variables and a year trend. Intervention on behalf of the rebels clearly increases the risk of conflict escalation as anticipated. The effect of pro-government intervention is the opposite, though it is less robust (it is not statistically significant if we look at all wars, though the effect is strong for ethnic wars alone). In light of the fact that intervention is unlikely to be assigned randomly across cases and unobserved country heterogeneity could explain why there is intervention in some countries but not others, we re-estimate the model using conditional (fixed effects) logit, which exploits withincluster variation to identify the effect of intervention. Any selection effects that operate at the country level should be addressed in these regressions. We find that the results are very strong in these models for both types of intervention, which gives us more confidence in our findings (columns 3 and 4$).{ }^{12}$

\footnotetext{
${ }^{12}$ What these regressions cannot establish is the causal direction of the relationship as escalating conflicts might invite intervention. New data would be required to address this point. Yet this correlation is also
} 


\section{Insert Table 2 here}

Finally, in models 5 and 6 we add a number of controls, drawing from the large literature on civil wars. We include per capita income (lagged one year), population size (lagged one year), oil dependence, elevation difference, ethnic and religious fractionalization. These are all standard controls in civil war regressions so we do not expand on the logic of adding them to the model. We describe data sources in our supplement and present more robustness tests using additional controls (including political discrimination of ethnic groups; ethnic polarization, and regime type). The addition of controls diminishes the magnitude of the effects of intervention, but the effects are still significant.

This empirical analysis is not exhaustive, but it does establish the plausibility of our theoretical claims about the effects of intervention on conflict escalation. Missing from these models is a control variable for ethnic polarization. We do not include it because all existing cross-country empirical measures of polarization merely measure group difference across a single dimension (usually language) and polarization measures are merely capturing differences in the demographic sizes of groups (e.g. Montalvo and Reynal-Querol 2005). As we discuss in our theory section below, this is the wrong way to think about polarization, which is inherently a concept that encapsulates the history of interaction between groups. Polarization is higher as the ideological distance between groups grows. ${ }^{13}$ While that cannot yet be captured in cross-country regressions, we capture this concept of polarization in our model by combining the demographic sizes of groups with a measure of psychological distance that divides those groups. Since available cross-country measures of polarization do not correspond to the theoretical concepts, we return to the analysis of the effects of polarization in interaction with intervention in our theoretical model and in case-studies that we present after the model. The model begins by considering how intervention can

informative and helps motivate the model that follows. Our case evidence is better suited to address the question of endogeneity of intervention and the interplay between intervention and social identification.

${ }^{13}$ As we explain below, ideological or psychological "distance" can be a function of history, politics, past conflict and any number of other variables that shape the salience of social identification. 
escalate conflicts over autonomy or secession, which are the equivalent of "ethnic" conflicts in the regressions shown above. We later consider how intervention interacts with ethnic distance in conflicts over control of the central government.

\section{The Basic Model: Conflict over autonomy or seces- sion}

In this section, we develop our model, beginning with the case where a distinct group demands autonomy or secession; we consider the case of challenges to the central government in the appendix. We focus on settings in which one or two third parties could influence the emergence and evolution of domestic conflict within a country. Examples of such settings include both regional conflicts such as the Kashmir conflict in India, in which Pakistan is a third party, as well as many civil wars and rebellions during the Cold War period that could be considered as proxy wars between the two superpowers of the time.

For the country concerned, we consider the interaction between the central government that is associated with a particular group or class $A$ and a region, group or class, denoted by $B$, that seeks autonomy, secession or greater accomodation at the center. The main third party that we consider is a potential sponsor of $B$, denoted by $B^{*}$, who might provide support for a rebellion and possible guarantees of economic support following autonomy. We do not examine $B^{*}$ s optimizing choices but only consider how changes in support parameters in favor of $B$ would change the likelihood or rebellion and civil war. We can also consider the effects of a potential third-party sponsor for the government, denoted by $A^{*}$, on the likelihood of war as well. ${ }^{14}$

The interaction of $A$ and $B$ involves both material and non-material concerns. The material source of potential dispute has a total size of $Y$; that could consist of natural resource rents, income from public-sector enterprises, or dedicated tax revenue. We suppose

\footnotetext{
${ }^{14}$ Cunningham (2016) considers this question and argues that pro-government intervention reduces the risk of civil war since it reinforces the power asymmetry relative to rebels.
} 
that under a status quo arrangement, $A$ receives a $\gamma \in(0,1)$ share of $Y$ with the remainder $1-\gamma$ share retained by $B$. This division of the economic surplus could be the result of a previous agreement between the two groups or fixed by the government, perhaps even fixed strategically as a way of deterring rebellion. The main source of non-material payoffs we consider is the possible alienation that members of $B$ might feel when they are under the rule of $A .{ }^{15}$ In particular, we assume that members of $B$ incur an alienation or distance cost $\Delta>0$ in any state of the world that does not involve Autonomy. ${ }^{16}$ We perceive distance $\Delta$ as partly a function of how different the minority group's attributes are from the majority group and partly a function of the history of conflict or cultural differences between the groups.

The share of the population belonging to group $A$ is $\alpha \in(0,1)$, with $1-\alpha$ being the share or $B$. Given the populations shares and the distance $\Delta$, the quantity $\alpha^{2}(1-\alpha) \Delta+$ $(1-\alpha)^{2} \alpha \Delta=\alpha(1-\alpha) \Delta$ represents the most common measure of polarization (Esteban and Ray, 2011, equation (4)). The closer is $\alpha$ to $1 / 2$ (that is, the more equal are the two groups) and the higher is the distance measure $\Delta$, the higher is the polarization of the country.

We assume that the decisions are made by the elites of $A$ and $B$ that reflect the wishes of their respective groups, in the sense that they maximize the groups' total payoff. The first decision that the leaders of group $B$ make is whether to choose the status quo or prepare for rebellion. Under the status quo the payoffs of the two groups are as:

$$
\begin{aligned}
U_{a}^{q} & =\gamma Y \\
U_{b}^{q} & =(1-\gamma) Y-(1-\alpha) \Delta
\end{aligned}
$$

The elites of the region can prepare for a rebellion that can have three possible outcomes. The first two outcomes occur in the event of war: victory and defeat occur with the

\footnotetext{
${ }^{15}$ We assume that members of $A$ do not incur an alienation cost because they control political power.

${ }^{16}$ As modeled in Sambanis and Shayo (2013) and Sambanis, Skaperdas, and Wohlforth (2015), non-material concerns can also include prestige or status payoffs. In turn, such payoffs can depend on the level of conflict between the two groups. Including such payoffs for both $A$ and $B$ would not change the qualitative results of the model.
} 
probability of each outcome depending on the relative military capabilities of the insurgents and the central government of the country. Victory for the rebels would lead to Autonomy whereas defeat would lead to continued rule under the central government as well as loss of material income $(1-\gamma) Y$. The third possible outcome after rebellion is for the two parties to negotiate a settlement that takes place under the threat of war. In that case the rebels would still remain under the central government's rule but might receive a higher share of material income.

Let $m_{a}$ and $m_{b}$ denote the military efforts of the Government and the rebels. We suppose that the probabilities of the Government and the rebels winning in the event of War are:

$$
p_{a}=\frac{m_{a}}{m_{b}+m_{a}}, p_{b}=1-p_{a}=\frac{m_{b}}{m_{b}+m_{a}}
$$

The sequence of moves in case $B$ chooses the path of rebellion are as follows:

1. $A$ and $B$ choose simultaneously $m_{a}$ and $m_{b}$ military efforts.

2. $A$ makes a Settlement offer to $B$ which consists of a division of $Y$.

3. $B$ either accepts or rejects the offer made by $A$. If they accept, the payoffs of $A$ and $B$ are in accordance with the offer. If they reject the offer, War takes place with the probabilities of winning described in (2).

In case of War, the expected payoffs of the two sides are:

$$
\begin{aligned}
U_{a}^{w} & =p_{a} Y+\left(1-p_{a}\right) 0-F-c_{a} m_{a} \\
U_{b}^{w} & =p_{a}(-(1-\alpha) \Delta)+\left(1-p_{a}\right)\left(Y+S_{b}^{*}\right)-F-c_{b} m_{b}
\end{aligned}
$$

An explanation of these expected payoffs is in order, starting with the Government. When the Government wins (with probability $p_{a}$ ) it receives the whole contested economic payoff $Y$, while when it loses (with probability $1-p_{a}$ ) it receives nothing. ${ }^{17}$ From these expected

\footnotetext{
${ }^{17}$ Of course, the government does receive other payoffs but, because they are constant and the two sides are risk neutral, there is no reason to take them into account here as they would merely be a notational burden without bringing about any difference in the results.
} 
terms, there are two terms that are subtracted. First, both sides pay costs of war $F(>0)$ that could include destruction, collateral damage, and additional military expenditures due to actual conflict taking place. Second, there are the costs expended on military resources. The marginal (and average) cost of these expenditures depend on several factors. The parameter $c_{a}$ (and $c_{b}$ for $B$ ) can be thought to represent fixed capital and organizational inputs into military capacity, with higher levels of capital and organizational inputs yielding a lower marginal cost of military resources. ${ }^{18}$ We can expect a government to have higher (perhaps much higher) levels of capital equipment and organization than the (potential) rebels. However, the latter could obtain help from their sponsor $B^{*}$ (as can the Government receive support from their own sponsor $\left.A^{*}\right)$.

The expected payoff for the rebels (group $B$ ), in addition to the cost elements we just described, leads to $-(1-\alpha) \Delta$ when they lose (with probability $p_{a}$ ). When they win (with probability $1-p_{a}$ ) they not only obtain the full contested material payoff $Y$ and they avoid $-(1-\alpha) \Delta$ due to autonomy, but they could also expect $S_{b}^{*}$ economic benefits that their sponsor might have promised. ${ }^{19}$

\section{Instruments of external intervention}

Third parties can affect the interaction of $A$ and $B$ in several different ways. We now explain the potential instruments that $B^{*}$ (and $\left.A^{*}\right)$ might use in intervening. First, the sponsor $B^{*}$ could make promises and even commitments of economic assistance in the event

\footnotetext{
${ }^{18}$ Total military capacity could be modeled as a function of two inputs, a fixed input $K$ (representing capital and organizational capacity) and a variable input $L$.

To see how $c_{i}(i=a, b)$ can reflect the marginal cost of variable inputs suppose that military capacity is determined by the production function $m_{i}=K_{i}^{\beta} L_{i}$ where $\beta>0$. Then the variable cost function (with capital $K_{i}$ fixed and its cost sunk) is obtained by solving the following problem (with $w$ representing the cost of $\left.L_{i}\right)$ :

$\min _{L_{i}} w L_{i}$ subject to $m_{i}=K_{i}^{\beta} L_{i}$

which readily yields

$c\left(m_{i}\right)=\frac{w}{K_{i}^{\beta}} m_{i}$.

We can then define $c_{i} \equiv \frac{w}{K_{i}^{\beta}}$.

Note that the greater the amount of capital and organizational capacity $\left(K_{i}\right)$, the lower is the marginal cost of production.

${ }^{19}$ These benefits are only available given autonomy and could take several forms as we explain below (e.g. trade agreements, and so on).
} 
$B$ manages to gain autonomy. Direct grants, investment, loan facilities, technical assistance, trade deals and preferential access to $B^{* \prime} s$ markets on the part of an autonomous $B$ could all be part of such economic benefits. Whereas $A^{*}$ could also make such commitments to similarly help $A$, the effects are not symmetric. Since $A$ represents a sovereign government it would be hard for $A^{*}$ to condition such help only on a victory in the event of a civil war. Without such conditions, the effect of general economic subsidies of $A^{*}$ to $A$ would not affect the incentives of $A$ or $B$ on whether or not we have the status quo, rebellion with settlement or rebellion with civil war as an equilibrium outcome. ${ }^{20}$

Second, the third parties could directly finance part of the variable military expenditures of their respective clients in the event of rebellion. That is, $B^{*}$ could subsidize $m_{b}$ and $A^{*}$ could subsidize $m_{a}$. It is known, however, that the equilibrium choices of $m_{a}$ and $m_{b}$ are independent of the subsidies as long as the subsidies do not exceed their equilibrium levels. Yet, whereas the marginal conditions do not change, the effects of such subsidies on the two sides are different: they do not affect the incentives of the Government side $A$ (because it is not the goverment that chooses to rebel), but they could change the incentives of side $B$ in moving into rebellion and civil war. ${ }^{21}$

The third instrument that the third parties could use to intervene involves changing the capital or organizational military capacity of their respective clients, that is, changing the marginal costs $c_{a}$ and $c_{b}$. As we will show, changing these marginal costs does change the incentive of the clients to invest in military resources themselves and the overall equilibrium outcome (see Chang et al (2007) for an analysis of this type of intervention).

Finally, a fourth instrument could be unrestricted subsidies directly provided by $B^{*}$ as long as $B$ is fighting regardless of the probability of winning and independent of the outcome.

\footnotetext{
${ }^{20} \mathrm{~A}$ different form of indirect intervention might be for $A^{*}$ to subsidize $A$ conditional on settling with $B$ without fighting. In effect, because that would create incentives for $B$ to rebel to gain a better settlement, this could constitute an indirect subsidy from $A^{*}$ to $B$. We do not consider that form of intervention for two reasons. First, the external actor no longer acts as a sponsor of $A$ but effectively as a sponsor of $B$. Second, if $A^{*}$ is motivated by a desire to avoid war without encouraging rebellion, then it can increase direct military or other subsidies to $A$ so as to increase the costs of rebellion to $B$.

${ }^{21}$ We do not consider such cases because we assume that the intervening power would find alternative, more cost-effective ways to affect the interaction between the two groups.
} 
This has the same effect as the military subsidies and they can induce rebellion and civil war. $A^{*}$ can offer a similar subsidy to $A$ conditional on reaching the stage of war (but it is $B$ that has the choice to rebel).$^{22}$

We now turn to examining the possible subgame perfect equilibrium outcomes, starting with last stage 3 of the sequence of moves described above. At that stage, $B$ will have already paid its military expenditures that are not included in the cost of conflict $F$ (that is, $c_{b} m_{b}$ will have already been sunk) and therefore it will accept any share $1-\eta$ of $Y$ if and only if:

$$
(1-\eta) Y-(1-\alpha) \Delta \geq U_{b}^{w}+c_{b} m_{b}
$$

Otherwise, War will take place. Then, in stage $2 A$ would only make an offer that satisfies (4) as an equality and the resulting Settlement payoff for $A$ is at least as great as $U_{a}^{w}+c_{a} m_{a}$. That is, denoting by $\eta^{*}$ the $\eta$ that satisfies (4) as an equality, $A$ will make an offer that $B$ will accept only if

$$
\eta^{*} Y \geq U_{a}^{w}+c_{a} m_{a}
$$

Given (3), and adding (4) and (5), Settlement is thus assured if

$$
2 F \geq\left(1-p_{a}\right)\left(S_{b}^{*}+(1-\alpha) \Delta\right)
$$

Settlement is possible if the costs of conflict $(2 F)$ are sufficiently high. How high they can be in order to avoid War depends on the probability of the rebel group $B$ winning $\left(1-p_{a}\right)$, the subsidy expected from the foreign sponsor $\left(S_{b}^{*}\right)$, and the distance the rebel group has from the government-controlling group $(\Delta)$ as well as the size of the group $(1-\alpha)$. Conversely, the higher are these values, the higher is the chance of War. Note that War is possible in this setting without incomplete information, misperceptions, optimism, or commitment problems on the part of either party. Moreover, even in the absence of the distance $\Delta$ War could still occur under a sufficiently high expected subsidy from the foreign sponsor.

Whereas the parameters $F, \alpha, \Delta$, and $S_{b}^{*}$ are exogenous, the probabilities of winning, $p_{a}$ and $1-p_{a}$ are endogenous. The probabilties of winning are determined by the equilibrium

\footnotetext{
${ }^{22}$ If $B$ knows that such a subsidy is available to $A$, this could deter $B$ from rebelling in the first place.
} 
choices of military resources under War with the payoff functions in (3). Taking (2) into account, the equilibrium choices, denoted by $m_{a}^{w}$ and $m_{b}^{w}$, are determined by simultaneously solving the following two derivatives of $(3)$ :

$$
\begin{aligned}
& \frac{\partial U_{a}^{w}\left(m_{a}^{w}, m_{b}^{w}\right)}{\partial m_{a}}=\frac{m_{b}^{w}}{\left(m_{a}^{w}+m_{b}^{w}\right)^{2}} Y-c_{a}=0 \\
& \frac{\partial U_{b}^{w}\left(m_{a}^{w}, m_{b}^{w}\right)}{\partial m_{b}}=\frac{m_{a}^{w}}{\left(m_{a}^{w}+m_{b}^{w}\right)^{2}}\left(Y+S_{b}^{*}+(1-\alpha) \Delta\right)-c_{b}=0
\end{aligned}
$$

Note how these first-order conditions indicate that the "prize" of the war-contest for $A$ is the disputed material payoff $Y$, but for $B$ the prize is $Y+S_{b}^{*}+(1-\alpha) \Delta$, because $B$ by winning, does not only gain $Y$ but also gains the expected subsidy from its sponsor $\left(S_{b}^{*}\right)$ and avoids the distance cost $(1-\alpha) \Delta$. This is a source of asymmetry in the War contest, in addition to the other asymmetries of the model that can be expected to have an effect on the choices of military efforts. Solving for $m_{a}^{w}$ and $m_{b}^{w}$ we obtain:

$$
\begin{aligned}
m_{a}^{w} & =\frac{c_{b}\left(Y+S_{b}^{*}+(1-\alpha) \Delta\right) Y^{2}}{\left[c_{b} Y+c_{a}\left(Y+S_{b}^{*}+(1-\alpha) \Delta\right)\right]^{2}} \\
m_{b}^{w} & =\frac{c_{a} Y\left(Y+S_{b}^{*}+(1-\alpha) \Delta\right)^{2}}{\left[c_{b} Y+c_{a}\left(Y+S_{b}^{*}+(1-\alpha) \Delta\right)\right]^{2}}
\end{aligned}
$$

The military effort of $A$ is (i) increasing in $A$ 's "prize" $Y$; (ii) increasing in the opponent's marginal cost and (iii) decreasing in own marginal cost $c_{b}$. The symmetric properties hold for the military effort chosen by $B$. By substituting (8) into (2) we obain the probabilities of winning under War:

$$
\begin{aligned}
p_{a}^{w} & =\frac{c_{b} Y}{c_{b} Y+c_{a}\left(Y+S_{b}^{*}+(1-\alpha) \Delta\right)} \text { and } \\
p_{b}^{w} & =1-p_{a}^{w}=\frac{c_{a}\left(Y+S_{b}^{*}+(1-\alpha) \Delta\right)}{c_{b} Y+c_{a}\left(Y+S_{b}^{*}+(1-\alpha) \Delta\right)}
\end{aligned}
$$

Each side's probability of winning depends (i) positively on own "prize" and negatively on the opponent's one; (ii) positively on own size and negative on opponent's size; and (iii) negatively on own marginal cost of military resources and positively on that of one's opponent. The higher "prize" for $B$ (due to the subsidy $S_{b}^{*}$ and avoiding the distance cost 
of $(1-\alpha) \Delta$ in case of a win) is thus a force counteracting the disadvantage that comes from a lower size and, presumably, higher marginal cost $c_{b}$ relative to the govenrment's.

By substituting (9) into (5), we obtain that War would ensue only if the following inequality were to be satisfied: ${ }^{23}$

$$
2 F<\frac{c_{a}\left(Y+S_{b}^{*}+(1-\alpha) \Delta\right)}{c_{b} Y+c_{a}\left(Y+S_{b}^{*}+(1-\alpha) \Delta\right)}\left(S_{b}^{*}+(1-\alpha) \Delta\right)
$$

This inequality includes the combinations of solely exogenous parameter values for which War could occur. We summarize its implications as a Proposition.

Proposition 1 Conditional on B choosing to rebel, War can occur only if inequality (10) were to hold. Then War is more likely, (i) the higher is the external subsidy $S_{b}^{*}$; (ii) the higher is the distance $\Delta$ felt by group B; (iii) the lower is the cost of War F; (iv) the lower is group $B^{\prime} s$ marginal cost parameter $c_{b}$ (and the more this parameter is lowered by subsidies from $\left.B^{*}\right)$; (v) the higher is the cost parameter $c_{a}$ of $A$; (vi) the higher is the population of $B$ (the lower is $\alpha$ ); and (vii), by combining (ii) and (vi), for $a>1 / 2$ the higher is the polarization index $\alpha(1-\alpha) \Delta$. [For the proof, please see the Appendix.]

Empirically, this Proposition implies that ethnic or other type of polarization is neither necessary nor sufficient for civil war if polarization is understood only in terms of demographic sizes of groups; but higher cultural or ideological distance or external intervention can increase the risk of civil war in a country with large (and roughly equal-size) ethnic groups. This proposition is consistent with the empirical results we showed earlier, where a purely demographic measure of ethnic polarization is only associated with civil war during the Cold War period when interventions and proxy wars were more frequent. Furthermore, whereas large enough $S_{b}^{*}$ or $\Delta$ (external subsidies or ethnic distance) can induce War by themselves, none of the other factors can do so without complementing at least one of $S_{b}^{*}$ or $\Delta$. The interaction effect of the Cold War variable and polarization reported in Table 1

\footnotetext{
${ }^{23}$ Whereas this inequality is necessary for War to occur, Settlement might still be theoretically possible if the government could find a best response to $m_{b}^{w}$ in stage 1 that would induce a Settlement offer by the government in stage 2 that would be accepted by $B$ in stage 3 of the game.
} 
is also consistent with the simultaneous presence of high levels of $S_{b}^{*}$ and $\Delta$ increasing the chance of War in the model.

Let $M_{b}^{*}$ denote a direct subsidy that $B$ receives from $B^{*}$ as long as $B$ engages in rebellion and which can be used for either military purposes or just consumption. Then, for future reference, the equilibrium payoff of $B$ under War equals: ${ }^{24}$

$$
\begin{aligned}
V_{b}^{w} & =p_{a}^{w}(-(1-\alpha) \Delta)+\left(1-p_{a}^{w}\right)\left(Y+S_{b}^{*}\right)-c_{b} m_{b}^{w}-F+M_{b}^{*} \\
& =p_{a}^{w}(-(1-\alpha) \Delta)+\left(1-p_{a}^{w}\right)\left(Y+S_{b}^{*}\right)-p_{a}^{w}\left(1-p_{a}^{w}\right)\left(Y+S_{b}^{*}+(1-\alpha) \Delta\right)-F+M_{b}^{*} \\
& =p_{a}^{w}\left(2-p_{a}^{w}\right)(-(1-\alpha) \Delta)+\left(1-p_{a}^{w}\right)^{2}\left(Y+S_{b}^{*}\right)-F+M_{b}^{*}
\end{aligned}
$$

If (10) were to be reversed, then Settlement under the threat of War would be feasible and an acceptable offer by $A$ could be found that would be consistent with a subgame perfect equilibrium. In that case, however, note that both War payoffs in (3) would be the appropriate payoff functions for the case of Settlement under the threat of War. Whereas $B^{\prime} s$ payoff function would be the same as in (3) (because $A$ receives all the possible surplus as he makes a take-it-or-leave-it offer), ${ }^{25} A^{\prime}$ 's payoff functions should equal $\eta^{*} Y$ where $\eta^{*}$ is the $\eta$ that satisfied (4) as an equality. It turns out, then, that the payoff functions under Settlement are the following:

$$
\begin{aligned}
U_{a}^{s} & =p_{a}\left(Y+S_{b}^{*}+(1-\alpha) \Delta\right)-\left(S_{b}^{*}+(1-\alpha) \Delta\right)+F-c_{a} m_{a} \\
U_{b}^{s} & =p_{a}(-(1-\alpha) \Delta)+\left(1-p_{a}\right)\left(Y+S_{b}^{*}\right)-F-c_{b} m_{b}
\end{aligned}
$$

Note that even under Settlement the payoffs of the two sides ultimately depend on their

\footnotetext{
${ }^{24}$ To determine the equilibrium payoffs under War, we need to substitute into (3) the equilibirum military resources in (8) and the equilibrium probabilities in (9). Note that the equilibrium cost of military resources for $B$ is:

$c_{b} m_{b}^{w}=\frac{c_{b} c_{a} Y\left(Y+S_{b}^{*}+(1-\alpha) \Delta\right)^{2}}{\left[c_{b} Y+c_{a}\left(Y+S_{b}^{*}+(1-\alpha) \Delta\right)\right]^{2}}=\frac{c_{b} Y c_{a}\left(Y+S_{b}^{*}+(1-\alpha) \Delta\right)}{\left[c_{b} Y+c_{a}\left(Y+S_{b}^{*}+(1-\alpha) \Delta\right)\right]^{2}}\left(Y+S_{b}^{*}+(1-\alpha) \Delta\right)=p_{a}^{w}\left(1-p_{a}^{w}\right)\left(Y+S_{b}^{*}+\right.$ $(1-\alpha) \Delta)$

${ }^{25}$ Under bargaining protocols different than the "ultimatum" bargaining that we have here, the payoff of $B$ under Settlement would not be identical to the payoff under War. Alternative bargaining protocols include a more complex alternating-offers game or the adoption of a bargaining solution such as the Nash or KalaiSmorodinsky solution. However, especially because utility is transferable in our game, the qualitative results would be the same as the one we adopt here. For an overview of bargaining under the threat of fighting, see Skaperdas (2006). How different bargaining solutions may affect arming when utilitly is non-transferable, see Anbarci et. al. (2002).
} 
probabilities of winning, which depend in turn on the military efforts chosen by each side. This is so because the disagreement payoffs are the ones driving bargaining and these payoffs are the War payoffs. Moreover, the "prize" for $A$ is now the same as that for $B$ (i.e., $\left.Y+S_{b}^{*}+(1-\alpha) \Delta\right)$ instead of just $Y$ because the subsidy from $B^{*}$ and the distance cost $(1-\alpha) \Delta$ are part of total "pie" that the two sides bargain over.

In the Appendix we derive the equilibrium military efforts and winning probabilities under Settlement. We can then derive the equilibrium payoff under Settlement by subsituting the equilibirum military efforts and probabilities of winning in (11) and adding $M_{b}^{*}$ :

$$
V_{b}^{s}=p_{a}^{s}\left(2-p_{a}^{s}\right)(-(1-\alpha) \Delta)+\left(1-p_{a}^{s}\right)^{2}\left(Y+S_{b}^{*}\right)-F+M_{b}^{*}
$$

where $p_{a}^{s}\left(=\frac{c_{b}}{c_{b}+c_{a}}\right)$ is $A^{\prime} s$ probbaility of winning under Settlement. For rebellion to occur, it is necessary that either $V_{b}^{w}$ or $V_{b}^{s}$ is greater than the status quo payoff $U_{b}^{q}=(1-\gamma) Y-(1-\alpha) \Delta$. In the Appendix we also provide conditions under which different types of subgame perfect equilibria can occur.

The main issue that we turn to next is the factors that determine the threshlods that would bring about a rebellion, with or without War. To see the incentives for rebellion, we first note that $B^{\prime} s$ payoffs under rebellion, $V_{b}^{w}$ and $V_{b}^{s}$, are both decreasing in $A^{\prime} s$ respective probabilities of winning (and increasing in the probabilities of winning of $B$ ). ${ }^{26} B^{*}$ can increase $B^{\prime} s$ winning probability by subsidizing the decrease in $B^{\prime} s$ marginal cost $c_{b}$ and, in the case of the probability under War, by increasing the subsidy $S_{b}^{*}$ in the case of Autonomy. A decrease in $\alpha(>1 / 2)$, which increases the measure of polarization, also increases $B^{\prime} s$ probability of winning and thus increases the likelihood of rebellion. As far as the probabilities of winning are concerned, $A^{*}$ can only counteract by subsidizing a reduction in the marginal cost of arming of their client $A\left(c_{a}\right)$. $B^{*}$ can also directly induce $B$ to rebel with a sufficiently high direct subsidy $M_{b}^{*}$ or, equivalently, by directly subsidizing military 0 .

${ }^{26}$ In particular, for both $i=w, s$, using $(14)$ or $(15)$ we have: $\frac{\partial V_{b}^{i}}{\partial p_{a}^{i}}=-2\left(1-p_{a}^{i}\right)(1-\alpha) \Delta-2\left(1-p_{a}^{i}\right)\left(Y+S_{b}^{*}\right)<$ 
expenditures. $A^{*}$ cannot use a similar instrument to support their client because their client is not making the decision to rebel or not.

To more clearly see the conditions necessary for either type of rebellion, it can be shown using (1) and (11) or (13) that $V_{b}^{i}>U_{b}^{q}$ (for either $\left.i=s, w\right)$ is equivalent to

$$
\left(1-p_{a}^{i}\right)^{2}\left(Y+S_{b}^{*}+(1-\alpha) \Delta\right)+M_{b}^{*}-(1-\gamma) Y>F
$$

The first term of the left-hand side of this inequality reflects the net gains from rebellion. In case of Autonomy the rebels receive all contested income $Y$ plus the expected subsidy from their sponsor $S_{b}^{*}$ and they avoid the distance cost $\Delta$ that direct rule under $A$ brings in all other circumstances. These net gains are multiplied by $\left(1-p_{a}^{i}\right)^{2}$, a term that reflects their probability of winning as well as incorporating (in its derivation) the costs of arming. We summarize this and other implications of (14) in Proposition 3.

Proposition $2 A$ rebellion by $B$ is more likely (i) the higher is the distance cost $\Delta$; (ii) the higher are the subsidies by $B^{*}$ to $B\left(S_{b}^{*}, M_{b}^{*}\right.$, and those that lower $\left.c_{b}\right)$; (iii) the lower is the share of $A^{\prime}$ s population $\alpha(>1 / 2)$; (iv) the lower is the share of contested income $(1-\gamma)$ received by $B$ under the status quo; (v) the lower is the subsidy given by $A^{*}$ to $A$ to lower $c_{a}$; (vi) the lower is the cost of War F; and (viii) by (i) and (iii), the higher is the polarization measure $\alpha(1-\alpha) \Delta$.

\section{When the rebels seek to overthrow the government}

Next, we consider modifications of the model presented above, where now the potential rebels are challenging the government's rule over the entire territory. The model is developed in the Appendix and we summarize the main differences and results here.

A key difference in the payoffs relative to the autonomy contest, is that when the rebels win the government now incurs a cost an alienation (distance) cost $a \Delta$ because they will no longer be in power and the rival group will control the state. In all other respects, the model is the same and the effects of external intervention are the same as in the autonomy 
model. The conditions that can induce rebellion by group $B$ are qualitatively similar as in the autonomy model, but the conditions that induce war are slightly different when we consider the role of distance between groups. The fact that the government now incurs losses $a \Delta$ when $B$ wins means that, under majority rule $(a>1 / 2)$, the government has more to lose from war than the rebels have to gain from war. In that case, the greater the distance $\Delta$ between government and rebels, the greater the social losses from war and the greater is the incentive to avoid war (and both sides will have greater incentives to settle). In the presence of a large enough external intervention that provides the rebels with subsidies $S_{b}^{*}$ war can still occur. If the government were to lose foreign subsidies in the event of war, then that would be an additional reason for the government to avoid war. If there is minority government $(a<1 / 2)$ then greater distance has the usual effect we found in the case of the autonomy model, increasing the expected social surplus from war, making war more likely to occur.

\section{Endogenous distance of identities}

Thus far we have assumed the distance between the two groups $(\Delta)$ to be exogenous to the actions undertaken by all parties or to the outcomes that may be induced by these actions. Rebellion and war, however, typically exacerbate differences between groups and the perceived distance between groups increases. If the two sides were to foresee such a possibility, they might hold back on inducing rebellion and war. Once, however, there is rebellion in the presence of the various instruments of external intervention the greater cleavage that has already been created between the two groups may well increase the chance of outright war. To allow for this, we now relax the assumption of exogenous $\Delta$ by following Sambanis and Shayo (2013) who, based on the empirical literature of the subject, model the perceived distance between the two groups depend on the level of total arming. ${ }^{27}$ In

\footnotetext{
${ }^{27}$ Group distance can also depend on the outcome that takes places such as whether there is Settlement, victory in War or loss in War as in Sambanis et. al. (2015) or on investments on nation-building that a state might undertake as in Alesina and Reich (2015). Our qualitative results would be similar under suitable assumptions on the effects that different outcomes have on group distance, whereas investments in
} 
particular, we have:

$$
\Delta=\Delta^{\prime}+\delta\left(m_{a}+m_{b}\right) \text { where } \Delta^{\prime}>0 \text { and } \delta \geq 0
$$

That is, group distance has a fixed component $\Delta^{\prime}$ and a variable component that depends on the total level of military expenditures of the two sides, with the parameter $\delta$ indicating the strength of this dependence on military expenditures.

Thus, once rebellion takes place and the two sides choose positive levels of military expenditures, whether in order to gain bargaining advantage in a prospective Settlement or to prepare for War, the perceived distance between the two groups increases. We examine two issues under this specification of endogenous distance of group identities: How the chance of War and the chance or rebellion change in view of the different possible forms of external intervention.

Given the endogeneity of $\Delta$, the payoff functions under War in (3) are now modified as follows:

$$
\begin{aligned}
U_{a}^{w^{\prime}} & =p_{a} Y+\left(1-p_{a}\right) 0-F-c_{a} m_{a} \\
U_{b}^{w^{\prime}} & =p_{a}\left[-(1-\alpha)\left(\Delta^{\prime}+\delta\left(m_{a}+m_{b}\right)\right]+\left(1-p_{a}\right)\left(Y+S_{b}^{*}\right)-F-c_{b} m_{b}\right.
\end{aligned}
$$

Since only group $B$, that is out of power, bears the distance cost, it is only the payoff function of $B$ that differs from (3). Using (2), the first-order conditions for an equilibrium are then the following:

$$
\begin{aligned}
\frac{\partial U_{a}^{w^{\prime}}\left(m_{a}^{w^{\prime}}, m_{b}^{w \prime}\right)}{\partial m_{a}} & =\frac{m_{b}^{w \prime}}{\left(m_{a}^{w \prime}+m_{b}^{w \prime}\right)^{2}} Y-c_{a}=0 \\
\frac{\partial U_{b}^{w^{\prime}}\left(m_{a}^{w^{\prime}}, m_{b}^{w^{\prime}}\right)}{\partial m_{b}} & =\frac{m_{a}^{w^{\prime}}}{\left(m_{a}^{w^{\prime}}+m_{b}^{w^{\prime}}\right)^{2}}\left(Y+S_{b}^{*}+(1-\alpha) \Delta^{\prime}\right)+\frac{m_{a}^{w^{\prime}}}{\left(m_{a}^{w^{\prime}}+m_{b}^{w^{\prime}}\right)^{2}}(1-\alpha) \delta\left(m_{a}^{w^{\prime}}+m_{b}^{w^{\prime}}\right) \\
-\frac{m_{a}^{w^{\prime}}}{\left(m_{a}^{w^{\prime}}+m_{b}^{w^{\prime}}\right)}(1-\alpha) \delta-c_{b} & =0
\end{aligned}
$$

Note that the second and third terms of $\frac{\partial U_{b}^{w^{\prime}}\left(m_{a}^{w^{\prime}}, m_{b}^{w^{\prime}}\right)}{\partial m_{b}}$ cancel each other out, eventually yielding two identical to those in (7) except that the originally exogenous $\Delta$ is replaced nation-building would obviously reduce the chance of rebellion and war. 
by the constant $\Delta^{\prime}$. This implies that the military expenditures are similar to (8) with the original $\Delta^{\prime}$ replaced by the constant $\Delta$ or

$$
\begin{aligned}
m_{a}^{w^{\prime}} & =\frac{c_{b}\left(Y+S_{b}^{*}+(1-\alpha) \Delta^{\prime}\right) Y^{2}}{\left[c_{b} Y+c_{a}\left(Y+S_{b}^{*}+(1-\alpha) \Delta^{\prime}\right)\right]^{2}} \\
m_{b}^{w^{\prime}} & =\frac{c_{a} Y\left(Y+S_{b}^{*}+(1-\alpha) \Delta^{\prime}\right)^{2}}{\left[c_{b} Y+c_{a}\left(Y+S_{b}^{*}+(1-\alpha) \Delta^{\prime}\right)\right]^{2}}
\end{aligned}
$$

With military expenditures under the expectation of War, therefore, the endogenously determined distance between the groups can be shown to equal:

$$
\Delta\left(m_{a}^{w^{\prime}}+m_{b}^{w^{\prime}}\right)=\Delta^{\prime}+\delta \frac{Y\left(Y+S_{b}^{*}+(1-\alpha) \Delta^{\prime}\right)}{c_{b} Y+c_{a}\left(Y+S_{b}^{*}+(1-\alpha) \Delta^{\prime}\right)}
$$

which is increasing in $\delta, \Delta^{\prime}$, and $S_{b}^{*}$ and decreasing in $c_{a}$ and $c_{b}$.

Under the expectation of Settlement the payoff functions of the two parties are as in (12) except $\Delta=\Delta^{\prime}+\delta\left(m_{a}+m_{b}\right)$. Following the same method as for the case of War, we can show that the equilibrium choices of military expenditures the following:

$$
\begin{aligned}
m_{a}^{s^{\prime}} & =\frac{c_{b}\left(Y+S_{b}^{*}+(1-\alpha) \Delta^{\prime}\right)}{\left(c_{b}+c_{a}\right)^{2}} \\
m_{b}^{s^{\prime}} & =\frac{c_{a}\left(Y+S_{b}^{*}+(1-\alpha) \Delta^{\prime}\right)}{\left(c_{b}+c_{a}\right)^{2}} \\
\Delta\left(m_{a}^{s^{\prime}}+m_{b}^{s^{\prime}}\right) & =\Delta^{\prime}+\delta \frac{\left(Y+S_{b}^{*}+(1-\alpha) \Delta^{\prime}\right)}{c_{b}+c_{a}}
\end{aligned}
$$

By substituting $\Delta\left(m_{a}^{w^{\prime}}+m_{b}^{w^{\prime}}\right)$ in (10) and either $\Delta\left(m_{a}^{w^{\prime}}+m_{b}^{w^{\prime}}\right)$ or $\Delta\left(m_{a}^{s^{\prime}}+m_{b}^{s^{\prime}}\right)$ in (14) we can obtain, respectively, the effect of the (now) endogenous distance cost in the likelihood of war conditional on rebellion (for the case of (10) and the likelihood of rebellion (for the case of (14). The effects of the variables $\delta, \Delta^{\prime}, S_{b}^{*}, c_{a}$, and $c_{b}$ are straightfoward to obtain and identical on both $\Delta\left(m_{a}^{w^{\prime}}+m_{b}^{w^{\prime}}\right)$ and $\Delta\left(m_{a}^{s^{\prime}}+m_{b}^{s^{\prime}}\right)$ and are summarized in the following Proposition.

Proposition: The endogenous distance cost whether there is War $\Delta\left(m_{a}^{w^{\prime}}+m_{b}^{w^{\prime}}\right)$ or Settlement under the threat of War $\Delta\left(m_{a}^{s^{\prime}}+m_{b}^{s^{\prime}}\right)$ is (i) increasing in the expected external 
subsidy $S_{b}^{*}$; (ii) decreasing in the marginal costs of military efforts $c_{a}$ and $c_{b}$; (iii) increasing in the constant term of the distance cost $\Delta^{\prime}$ and the sensitivity of the distance cost to military efforts $(\delta) . B y(10)$ and (14) it then follows that the same variables increase the chance of War and Rebellion.

These results show that two instruments of intervention that the foreign sponsor of the rebels has at its disposal $\left(S_{b}^{*}\right.$ and $\left.c_{b}\right)$ can be used to affect the chance of War and Rebellion by influencing the perceived distance between rebels and government. By increasing the expected subsidy to the rebels in the event of secession or autonomy or by decreasing the rebels' marginal cost of military expenditures, total military expenditures increase which, in turn, make rebels and government feel that they are further apart. In tunr, this increase in perceived distance makes War and Rebellion more likely, beyond what is contributed independently by the factors identified in Propositions 1 and 2 .

In other words, actual or expected intervention does not just shape the bargaining calculations of Karabagh Armenians, Abkhaz, Ossetians, Turkish Cypriots, Kosovo Albanians, and any other minority group considering rebellion; it also shapes their identity because the expectation of external support makes their ethnic identity more salient and makes the group feel more distant from the group controlling the state. The effect of foreign sponsors of the government on endogenous distance cost is similar and operates through the marginal cost of the government's military expenditures $\left(c_{a}\right)$. Because a subsidy that decreases this marginal cost increases military expenditures and, through this channel increases distance and the likelihood of War and Rebellion, the sponsors of the government who have an interest in avoiding war might have a reason to moderate the capital and organizational subsidies they provide to the government. ${ }^{28}$

\footnotetext{
${ }^{28}$ Note that by considering the endogenous identity channel we identify a mechanism through which external support for governments actually increases the risk of rebellion. Empirically, the net effect on rebellion will depend on the overall balance of power so it is possible that the distance effect (increasing the risk of war) will be overshadowed by the deterrent effect of arming the government where the existing power asymmetry also reduces the chances of victory for the rebels.
} 


\section{Case Evidence}

The model we have developed is consistent with cross-country evidence, including the large$\mathrm{N}$ data analysis that we presented earlier. The difficulty in testing the model via regression analysis is that the types of interventions that we have considered are often unobserved prior to the start of war. As mentioned earlier, existing datasets only code intervention for active conflicts. Therefore, it is not possible to test the effect of actual or expected intervention on conflict onset. Having gone as far as current data sources allow with the regression analyses presented earlier, we now provide direct case-based evidence that allows us to process-trace the effect of anticipated external intervention on conflict escalation and civil war onset. We follow a two-pronged strategy. First, we provide a medium-N comparison of cases from the post-Soviet space. These allow us to keep constant various unobserved country-level characteristics as well as historical antecedents of separatist movements while focusing on the role of anticipated intervention in the escalation of self-determination movements. We use a new data source on self-determination movements that includes more cases than any published database and we canvas the histories of all cases to find suggestive evidence connecting actual or anticipated intervention to violent conflict. Second, we provide a short, but in-depth analysis of the civil war in Ukraine that identifies the crucial role of several of the mechanisms posited by our theory. While earlier we drew on large-N data to show that intervention catalyzed the effect of polarization during the Cold War period, the case of Ukraine allows us to explore the same dynamic in the context of the new Cold War developing between the United States and Russia. The competing interventions and regional proxy wars now ongoing in the Middle East are reminiscent of the pre-1990 period.

\subsection{Post-Soviet Cases}

The Soviet collapse led to 15 new countries in 10 of which minorities threatened further rebellion seeking greater autonomy or secession (Roeder 2007, 303). The Self-Determination Movements Data Set (Sambanis, Germann and Schädel 2015), which covers all self-determination 
movements word wide, both violent and non-violent, codes 71 such movements in these 10 countries between 1991 and 2013. These struggles remained mostly non-violent and unfolded in a setting that holds constant a number of cultural, historical, institutional and other country-specific unobserved determinants of war onset. They offer sufficient variation in outcomes for us to explore the effect of anticipated external assistance on conflict escalation.

Intervention emerges as an important explanation for why some of these experienced major violence, while most $(87 \%)$ did not (see Table S1 in our supplementary appendix). Almost all the non-violent cases yield scant evidence of expectations of material assistance from other states. Many of these cases concern ethnic groups entirely within the Russian Federation with no international border and/or with no clear ethnic kin states abroad or other plausible external sponsors. Where expectations of external assistance existed, we find evidence connecting non-violent rebel-government bargains with new information that no external support was forthcoming. In 1993 Russia was in political crisis with the legislature containing powerful political figures suggesting support of compatriots abroad while the executive branch under Boris Yel'stin adopted a more restrained stance. Pre-2013 secessionism in Crimea, Ukraine's Donets'k coal basin ("Donbas"), Estonia, and Kazakhstan peaked precisely in this period with greatest uncertainty concerning potential official Russian support. All of these movements adapted to their host states after Yel'tsin crushed parliamentary opposition and ended ambiguity on Russia's stance. Similarly, within the Russian Federation, it was when independence-minded Tatarstan President Mintimer Shamiev determined that Turkey was unwilling to engage beyond business and cultural relations that he realized how vulnerable his republic was to Russian threats and ultimately reintegrated in 1994 (Roeder 2007, 315).

Nine cases experienced major violence. Of these, external intervention was highly salient in six (trans-Dniester Slavs in Moldova, Abkhaz and Ossets in Georgia, Armenians in Azerbaijan, and Pamiri Tajiks and Uzbeks in Tajikistan). The three remaining cases are in 
Russia's northern Caucasus (Chechens, Ingush and Dagestanis). Violence levels were minor in Dagestan and Ingushetia, but a full-blown civil war took place in Chechnya. In these cases, there was no overt state intervention but some covert state and non-state intervention from the Gulf region and elsewhere has been reported, so these cases, too, have elements that are consistent with the logic of the model though less so than the other cases. In those, intervention clearly affected how sub-state groups framed their identity, increased polarization within target states, helped feed escalated claims and gave relatively weak groups the wherewithal to take on or push back host-state efforts to regain authority over rebellious republics. Ossets were small in number and poorly organzied and Abkhazians were a minority in their own republic, yet with Russian aid they fought and beat the Georgian forces. As Driscoll (2015, 81) sums up the evidence: "Given the haphazard organization of these impromptu armies and the low quality of the recruits, it is not surprising that Russian military units intervened to settle almost every single decisive military battle fought on the former territory of the USSR." Without Russian help, for example, Georgia would have reoccupied the rebellious republics without passing casualty threshold to high level violence (Roeder 308-310; Human Rights Watch, 10). In Ajaria, by contrast, Georgia could issue an ultimatum and, lacking outside support, the leadership had to acquiesce.

In Moldova, Laitin $(2001,859)$ demonstrates the implications of "The unambiguous commitment by the 14th Army" in mobilizing violent resistance. That commitment was lacking in the other main independence-minded Moldovan region, Gagauzia, which had low expectations of outside support and reconciled with the government in Chisinau. In Moldova, Russophone elites were supported by Moscow starting with the deployment in September 1990 of Soviet Interior Ministry troops to protect the Congress that declared the independence of the Dniestr Republic. Prior to that summer Russian preferences were signaled by a "modest pro-Dniestrian bias in Gorbachev's efforts" managing the conflict in Moldova (Kaufman 1996, 129). According to Kaufman's account of the conflict, "every major escalatory action the Dniestrians took was preceded by a clear show of support from Moscow" 
(p. 130). More broadly, Laitin $(2001,859)$ argues that the external military commitment in Moldova, as well as "the commitment by the Armenian paramilitaries that were driving Armenian state policy in regard to Nagorno-Karabakh ... were the consequential differences that account for the violent secessions and differentiate these cases from Estonia, Latvia, Ukraine, and Kazakhstan, where secessionist war was avoided."

Needless to say, without better measures of polarization, distance and other key parameters in most of these cases conclusions regarding the relative importance of external intervention remain suggestive. Hence, a good strategy is to look in more detail at individual cases in which expectations of intervention change over time.

\section{$7.2 \quad$ Ukraine}

The upshot of the theory and evidence presented thus far is that intervention, which can result from patterns of inter-state competition in the international system, can make the difference between peaceful and violent resolution of inter-group conflict within target states. By most accounts, post-Soviet Ukraine is a case in point. Until the fall of 2013 scholars saw Ukraine as a case with all the preconditions that sparked violent civil conflict elsewhere across Eurasia, but where peace had been preserved (Snyder 1993; Posen 1993; Laitin 2001; Roeder 2007). The country contended with separatist sentiment in key regions, a weak, corrupt state and underperforming economy, a history rich with episodes waiting to be used by political entrepreneurs to feed ethnic nationalist grievance narratives, and a neighboring great power with political elements nurturing irredentism. According to standard measures, Ukraine's base potential for polarization could be understated because the country's subnational identities are also rooted in regional culture, traditions and affinities. ${ }^{29}$ Darden (2012) has shown that these identities were extremely salient, stemming from different timing and content of the scholastic revolution in different regions of the country as these regions at-

\footnotetext{
${ }^{29}$ Montalvo and Reynal-Querol's (2015) dataset omits Ukraine altogether. Fearon (2003) codes three groups in the Ukraine: Ukrainians, with $73 \%$ of the population, Russians (22\%) and Jews (1\%). Using EPR data (Cederman et al 2010), Ukraine's ethnic polarization score is about 0.67 , which is sightly above the 50 th percentile for all countries.
} 
tained mass literacy under different empires and states through time. As a result, even though over $80 \%$ of Ukraine's citizens register their nationality as Ukrainian, in practice the country's politics were conducted under the shadow of much more powerful ideological polarization with a latent rift waiting to be exposed (Katchanovski 2006; Kulyk 2016).

Yet as of the fall of 2013, there had been no violence for control of the government, secession or autonomy. Why did the peace last until then; and why did war break out in $2014 ?$

The dominant explanation for peace in post-Cold War Ukraine is that "democratic institutions allowed political elites to find peaceful resolutions to ... crises" (Kudelia 2016, 5; Kuzio 2015). In the terms of our model, governments in Kyiv maneuvered to prevent citizens affiliated with any one regional social identity from experiencing unacceptably high alienation or distance costs. In the background, however, this equilibrium depended on the absence of intervention. External powers were involved in Ukrainian politics through this period, but the forms of involvement never incentivized violence. In particular, though irredentist movements existed in Russia, after 1993 official policy gave scant hope to those in Crimea and Donbas seeking secession in order to join Russia (Kudelia 2016; Katchanovski 2016). Before 2013, in short, elites in Ukraine favoring secession and reunification with Russia had no reason to believe that were they to pursue that objective violently they would receive Russian backing, and so they worked within Ukraine's political institutions. As Darden $(2010,70)$ summarized the dominant expert view, "in practice Russia has been relatively restrained. An aggressive Russian policy toward its neighbors could have been successful in fomenting the secession of northern Kazakhstan, Crimea, and much of southern and eastern Ukraine . . ."

Increased intervention undermined this non-violent equilibrium in three ways in successive phase of the crisis. First, heightened competitive expectations of subsidies and other forms of external support from the west and Russia undermined the government's ability to ameliorate perceived distance from key regional identity groups, thus effectively contributing 
to Ukraine's growing polarization. The government of Viktor Yanukovych was considering a formal association with the EU that featured a "deep and comprehensive trade agreement" [DCTA] even as he was under pressure from Moscow to join Putin's Eurasian Union. Each of these agreements would have differential effects in different regions. Ukrainian industry was heavily dependent on Russian trade and implicit subsidies (Ickes and Gaddy, 2014) and much of that industry was located in the South and East, Yanukovych's base. Not only would association with the EU almost certainly spell the end of those subsidies, but officials in Brussels also made clear that it was not compatible with current and prospective trade arrangements between Russia and Ukraine. Fearing losses from curtailed Russian trade and subsidies, and presented with an attractive package of loans and aid from Putin, Yanukovych decided not to pursue the EU trade agreement and opted for Russia's Eurasian Union.

That decision seemed to mark the government's decisive association with its base regional identities in the east and south, increasing the distance perceived by those with a western regional identity. This effectively increased the country's polarization and sparked the Maidan movement, which emanated from regions with majorities that not only had identity-based reasons for favoring a western orientation and had less economically to lose from an end to existing economic relations with Russia but also had reason to believe that association with the EU would yield direct and indirect material benefit over the long term (considered as $S_{b}^{*}$ in our model). Apparent involvement of US officials in staffing Ukraine's new government against the backdrop of some $\$ 5$ billion in reported democracy assistance to the country all contributed as $c_{b}$ to the development of the Maidan movement and as $M_{b}^{*}$ (to induce rebellion) in addition to the $S_{b}^{*}$ from the EU agreement. The image of US Undersecretary of State Victoria Nuland distributing sandwiches during the Maidan protests was but one of many that gave force to those expectations. Expectations of intervention and associated increased polarization are thus both implicated in the Maidan rebellion, which sparked the collapse of the Yanukovich government.

The hastily assembled successor government, quickly backed strongly by the EU and the 
US, ushered to the next phase of the crisis. As in past political crises, distance became more salient whenever a specific regional identity was seen to be dominating the government's approach to defining the Ukrainian nation. This, in a nutshell, is what happened after the Euromaidan protests led to regime change (Sakwa 2016). Consistent with the model, we thus have a contest over autonomy in a highly polarized environment ( $\alpha$ close to $1 / 2$ and very high $\Delta)$ but, in contrast to all previous post-1991 crises, a large intervention $\left(S_{b}^{*}\right)$ made rebellion and war very likely. In late February and early March 2014, Russian special forces facilitated the annexation of Crimea. Once Russian elite forces appeared on the peninsula, most of the republic's governing apparatus - police, intelligence, ministries, most of the army, etc. - transferred its loyalty to Russia, enabling a quickly organized referendum and transfer of sovereignty in a matter of three weeks (Petrov 2016). These events, accompanied by heightened official nationalism and support for the "Novorossiya" idea in Russia, radically transformed expectations of intervention/support in other Ukrainian regions, notably Donbas.

This led to the second key intervention effect: increasing the appeal of the regional identity and emboldening insurgents in eastern Ukraine to ramp up demands and take armed actions that would otherwise have been unlikely. The correspondence between conflict escalation and the timing of the realization that Russian support was forthcoming is evident in Figure 1 below, which plots data on deaths compiled by the UCDP researchers (Sundberg and Melander 2013). ${ }^{30}$ The Crimea annexation is precisely proximate to the outbreak of war, with high fatality rates continuing until two overt Russian interventions in support of separatists in Ilovais'k (late August 2014) and Debal'tseve (Jan-Feb 2015) precipitated the Minsk I and II accords (respectively) and the conflict stalemated. Scholars debate the relative weight of indigenous causes (especially the breakdown in state authority in the region) versus the external factor (cf. Sakwa 2016; Wilson 2016). But even accounts meant to highlight domestic causes cast doubt on the counterfactual that the conflict would have esca-

\footnotetext{
${ }^{30}$ Data that can be aggregated to the monthly level, including year 2015, are available online: http://www.pcr.uu.se/research/ucdp/datasets/.
} 
lated to war in the absence of increased expectations of intervention (Arel and Driscoll 2015; Kudhelia 2015). As Wilson $(2016,632)$ concludes "Local actors would not have acted as they did without Russian support." Similarly Zhukov $(2015,3)$, whose focus is on economic incentives, concurs with the general view that "[e]mboldened by Crimea's annexation, many protesters were hopeful that Moscow would recognize their own referendum on independence, and even incorporate the region into the Russian Federation." The referenda in Donet'sk and Luhan'sk proclaiming the breakaway "people's republics" (DNR and LNR) radically reduced the bargaining range with Kyiv, making it much harder to find a non-violent solution.

\section{Insert Figure 1 here}

Potential rebels were presented with overwhelming evidence that the old equilibrium in which Moscow officials eschewed support for separatism was over. Once Crimea was in play, Russian official statements highlighting the "Novorossia" concept received wide coverage. Russian military maneuvers on Ukraine's border added urgency to the message. And, of course, expectations were borne out quickly, as Russian intelligence and logistical support for various rebel formations quickly materialized (International Criminal Court 2016, 37).

Abundant process-tracing evidence details how expectations of intervention fed actions that led to war, consistent with the mechanism underlying the model. For example, a key escalatory move was the lightning strike to seize government buildings in Slav"yans'k by the former Russian FSB officer Igor Girkin (aka "Strelkov") and his volunteers from Crimea. While "[i]t is uncertain whether Strelkov's initial involvement in Ukraine was officially sanctioned by the Russian government" (Ostanin 2014), the key is that his actions were initially successful and met with local elite and popular support in part because of widespread expectations that his vision for Donbas would be backed by Russia. Strelkov himself stressed that he was well aware of the effect of imitating the actions of the "little green men" in Crimea. According to him, the locals "openly expressed their sympathies for us" because they believed that "everything would be repeated as in Crimea" (quoted in Kudhelia 2015, 
14). At the end of March 2014, Strelkov predicted that "by summer Ukraine will not exist in its current form - the East and Southeast will declare independence, which Kyiv will not recognize, but will be powerless to counter, because Russia will stand behind the separatists."

Other aspects of the model are also consistent with experts' accounts of the case. Zhukov (2015) presents strong evidence that, more than any other Ukrainian region, Donbas confronted a "perfect economic storm" if Kyiv opted for the DCTA. Indeed, the storm had already hit in July 2013 as Russia responded to Kyiv's negotiations with the EU by imposing trade restrictions - felt acutely in Donbas by late fall - and promising much worse to come. All this evidence is consistent with the model's prediction that war risk is higher the lower the marginal costs $\left(c_{b}\right)$ of rebellion (due to lower wages in the rebel region), and the higher the $\gamma$ (lower share of the contested resource available to the rebels).

The third key intervention effect was to provide insurgents with the military wherewithal to beat back government efforts to reassert control. As in other violent post-Soviet cases, this is what helps to account for high casualty numbers. Given its covert nature, the precise scale and timing of Russia's military involvement are subject to some uncertainty, but a strong consensus places significant regular Russian forces in the Donbass from July on, and major flows of advanced weapons throughout (Sutyagin 2015). Ultimately, Russia is reported to have committed "tactical battalion groups" numbering in the several thousands of troops to major battles, in response to insistent pleas from Strelkov and other insurgents (Mitrokhin 2015, 245). Without that support, evidence strongly suggests that the Ukrainian state would have quashed the rebellion with far lower casualties. As President Lukashenka of Belarus stated in October 2014, "let's be honest, the days of the DNR and LNR would have been numbered long ago without Russia" (quoted in Wilson 2016, 629).

\section{Conclusion}

The theory and evidence presented here strongly suggest that as expectations or the reality of external intervention grow, so does the global problem of civil war. Not only can major 
powers funnel resources into ongoing intra-state conflicts and thereby prolong them and render them more sanguinary, as is well understood in the current literature, but through a variety of mechanisms that we identify the mere presence of increased interventionism in the international system can cause intra-group disputes within states to morph into violent conflicts. In a systemic setting conducive to high incidence of intervention, groups within states will be more likely to frame their understanding of social identity in ways that increase polarization, escalate demands for autonomy or control of the center, and fail to find waravoiding bargains.

Our model has profound implications for both the theoretical and empirical study of civil war. The type of conflicts that we observe (conflicts over secession or capture of the center) may depend on the type of incentives offered by foreign sponsors; and the types of groups that rise to challenge the state could also be endogenous to patterns of foreign intervention and great-power politics. The implications for the empirical study of conflict are significant. These influences have not yet been integrated in empirical models of civil war, but ommitting them is likely to bias inferences about when, why, and where civil wars occur.

From the perspective of theory, our model proposes a new approach to modeling civil war that puts inter-state politics at center stage. The model can serve as the springboard for more elaborate theories connecting intra-state and inter-state conflict. Material interests and psychological affinities connecting domestic groups and potential foreign sponsors could be modeled in a more complex framework that endogenizes the probability of intervention. The outcomes of civil war and their effects on competition between potential interveners could also be modeled in a framework that explores the implications of inter-state rivalries for domestic armed conflict (see Toukan 2017 for a promising new approach). Indeed, even the type of social cleavage that becomes relevant in structuring domestic conflict could be a function of international politics. Just as sectarian war in Iraq and now Syria was defined by the institutions that were built in the early phases of the American occupation in Iraq, so could interventions elsewhere determine if groups will organize along ethncity, sect, or 
political ideology. Our model therefore supports the argument that the relationship between ethnicity and conflict is contingent on the political context (Sambanis and Shayo 2013; Cederman et al 2010).

Substantively, the model's upshot is that even if we assume that major inter-state war will remain unlikely, merely increasing rivalry at the system level threatens to reverse the post-Cold War trend of decreasing prevalence of civil war. This dire potential highlights the need to integrate theory across the domestic and inter-state levels. In order to isolate intervention's effects on domestic settings, we treated the international system as exogenous, which allows us to highlight the strategic considerations of domestic actors. The crucial next task is to go beyond this approach. To do so, we need to revivify systemic theory-which is central to other social sciences and once was much more central to international relations research than it is now - but do so in a way that allows scholars to model interactions across the systemic, domestic-institutional, and individual level of analysis. The resurgence of ethno-nationalism around the world is at least partly the result of intervention in political conflicts by major powers. The outcomes of those interventions are increasingly bad - state failure in Libya, a failed occupation in Iraq, an Islamic proto-state carved out of Syria, zones of lawlessness and constant war in Central Asia, and waves of migrants from poor and warravaged countries in the Middle East, South Asia, and Sub-Saharan Africa perceived to be threatening the tenuous liberal-democratic balance in the West. A crucial task is to identify the conditions under which states might inculcate mutual restraint regarding intervention in third conflicts. The superpowers failed to do this in the Cold War, with baleful consequences. Today's major powers should try harder. To provide knowledge relevant to that task, scholars need to develop theories better suited to understanding system-domestic interactions than the rigidly segmented theories of the 20th century. 


\section{References}

Amegashie, J.A. 2010. "On Third-Party Intervention in Conflicts: An Economist's View." Peace Economics, Peace Science, and Public Policy 16 (2): 1-10.

Amegashie, J.A. 2014. "Asymmetric Information and Third-Party Intervention in Civil Wars." Defence and Peace Economics 25 (4): 1143-1174.

Amegashie, J.A., Kutsoati, E. 2007. "(Non)intervention in Intra-State Conflicts." European Journal of Political Economy 23: 754-767.

Anbarci, Nejat, Stergios Skaperas and Constantinos Syropoulos. 2002. "Comparing Bargaining Solutions in the Shadow of Conflict: How Norms against Threats Can Have Real Effects." Journal of Economic Theory 106 (1): 1-16.

Bas, Muhammet A. and Robert J. Schub. 2016. "How Uncertainty About War Outcomes Affects War Onset." Journal of Conflict Resolution 60 (6): 1099-1128.

Cetinyan, Rupen. 2002. "Ethnic Bargaining in the Shadow of Third-Party Intervention." International Organization 56 (3): 645-677.

Chang, Y.-M., Potter, J., Sanders, S. 2007. "War and Peace: Third-party Intervention in Conflict." European Journal of Political Economy 23: 954-974.

Collins, Kathleen. 2006. Clan Politics and Regime Transition in Central Asia. Cambridge: Cambridge University Press.

Cederman, Lars-Erik, Andreas Wimmer, and Brian Min. 2010. "Why Do Ethnic Groups Rebel? New Data and Analysis." World Politics 62 (1): 87-119.

Cederman, Lars-Erik, Luc Girardin, and Kristian Gleditsch. 2009. "Ethnonationalist

Triads: Assessing the Influence of Kin Groups on Civil Wars." World Politics 61 (3): 403437.

Chandra, Kanchan and Steven Wilkinson. 2008. "Measuring the Effect of 'Ethnicity'." Comparative Political Studies 41 (4-5): 515-563.

Cunningham, David E. 2016. "Preventing Civil War: How the Potential for International Intervention Can Deter Conflict Onset." World Politics 68 (2): 307-340. 
Cunningham, David E. 2010. "Blocking Resolution: How External States Can Prolong Civil Wars." Journal of Peace Research 47 (2): 115-27.

Darden Keith A. 2010. "Conditional Property and Regional Political Cultures: Challenges for U.S. Foreign Policy in the Post-Soviet Space," in Timothy Colton, Timothy Frye, and Robert Legvold, eds., The Policy World Meets Academia: Designing U.S. Policy toward Russia. Cambridge: American Academy of Arts \& Sciences, pp 70-78.

Driscoll, Jesse. 2008. "Inside The Leviathan: Coup-Proofing After State Failure." Stanford University. Working Paper

Driscoll, Jesse. 2015 Warlords and Coalition Politics in Post-Soviet States. Cambridge: Cambridge University Press.

Discoll. Jesse and Dominique Arel. 2016. "Ukraine's Civil War." UCSD Working Paper.

Doyle, Michael and Nicholas Sambanis 2000. "International Peacebuilding: A Theoretical and Quantitative Analysis." American Political Science Review 94 (4): 779-801.

Elbadawi, Ibrahim and Nicholas Sambanis. 2000. "External Intervention and the Duration of Civil Wars." Washington DC: World Bank Policy Research Working Paper 2433.

Esteban, Joan, and Debraj Ray. 2011. "Linking Conflict to Inequality and Polarization." American Economic Review 101 (4): 1345-74.

Esteban, Joan, Laura Mayoral, and Debraj Ray. 2012. "Ethnicity and Conflict: An Empirical Study." American Economic Review 102(4):1310-42.

Fearon, James D. 2003. "Ethnic and Cultural Diversity by Country." Journal of Economic Growth 8: 195-222.

Fearon, James. D. and David Laitin. 2003. "Ethnicity, Insurgency, and Civil War." American Political Science Review 97 (1): 75-90.

Grieco, Joseph M. 1988. "Anarchy and the Limits of Cooperation: A Realist Critique of the Newest Liberal Institutionalism." International Organization 42 (3): 485-507.

Grigorian, Arman. 2010. "Third-Party Intervention and the Escalation of State-Minority Conflicts." International Studies Quarterly 54: 1143-1174. 
Guimarães, Fernando Andresen. 1998. The Origins of the Angolan Civil War: Foreign Intervention and Domestic Political Conflict. Palgrave.

Hall, J.A. and S. Malesevic, eds. 2013. Nationalism and War. Cambridge University Press.

Ickes, Barry and Clifford Gaddy. 2014. "Ukraine: A Prize neither Russia not the West can Afford to Win." Brookings, May 22. https://www.brookings.edu/articles/ukraine-aprize-neither-russia-nor-the-west-can-afford-to-win/

International Criminal Court, Office of the Prosecutor. 2016. "Report on Preliminary Examination Activities" 14 November.

Jenner, Erin. 2004. "A Bargaining Theory of Minority Demands: Explaining the Dog that Did not Bite in 1990s Yugoslavia." International Studies Quarterly 48: 729-754.

Katchanovski, Ivan. 2006. "Regional Political Divisions in Ukraine in 1991-2006." Nationalities Papers 34 (5): 507-532.

Kaufmann, Stuart. 1996. "Spiraling to Ethnic War: Elites, Masses, and Moscow in Moldova's Civil War." International Security 21 (2): 108-138.

Kudelia Serhiy. 2016. "The Donbas Rift." Russian Politics and Law 54 (1): 5-27.

Kuperman, Alan. 2013. “A Model Humanitarian Intervention?: Reassessing NATO's Libya Campaign." International Security 38 (1): 105-136.

Kuzio, Taras. 2015. Ukraine: Democratisation, Corruption and the New Russian Imperialism Praeger.

Kydd, Andrew H. and Scott Straus. 2013. "The Road to Hell? Third-Party Intervention to Prevent Atrocities." American Journal of Political Science 57 (3): 673-684.

Laitin D. 2001. "Secessionist Rebellion in the Former Soviet Union." Comparative Political Studies 34(8): 839-861.

Menon Rajan and Eugene Rumer 2015. Conflict in Ukraine: the Unwinding of the PostCold War Order. MIT.

Mitrokhin, Nikolai. 2015. "Infiltration, Instruction, Invasion: Russia's War in the Don- 
bass." Journal of Soviet and Post-Soviet Politics and Society 1 (1): 219-50.

Montalvo, José G., and Marta Reynal-Querol. 2005. "Ethnic Polarization, Potential Conflict, and Civil Wars." American Economic Review 95 (3): 796-816.

Mylonas, Harris. 2013. The Politics of Nation-Building: Making Co-Nationals, Refugees, and Minorities. Cambridge: Cambridge University Press.

Ostanin, Iggy. 2014. "Russia Against the World: Igor Strelkov's Self-Fulfilling Prophecy" The Interpreter http://www.interpretermag.com/russia-against-the-world-igor-strelkovs-selffulfilling-prophecy/

Petersen, Roger D. 2001. Understanding Ethnic Violence. Cambridge: Cambridge University Press.

Petrov, Nikolai. 2016. "Transforming the Ukrainian Peninsula into a Russian Island." Russian Politics $\&$ Law 54 (1): 74-95.

Poast, Paul. 2015. "Lincoln's Gamble: Fear of Intervention and the Onset of the American Civil War." Security Studies 24: 502-527.

Posen, Barry R. 1993. "The Security Dilemma and Ethnic Conflict." Survival 35: 1: $27-47$.

Posner, Dan. 2004. "Measuring Ethnic Fractionalization in Africa." Americal Journal of Political Science 48 (4): 849-863.

Powell Robert. 2013. "Monopolizing Violence and Consolidating Power." Quarterly Journal of Economics 128 (2): 807-59.

Powell Robert. 2017. "Taking Sides in Wars of Attrition." American Political Science Review 111 (2): 219-236.

Roccas, S., \& Brewer, M.B. 2002. "Social Identity Complexity." Personality and Social Psychology Review, 6 (1): 88-106.

Roeder, P. 2007. Where Nation-States Come From: Institutional Change in the Age of Nationalism Princeton: Princeton University Press.

Regan, Patrick. 2000. Civil Wars and Foreign Powers. Ann Arbor: University of 
Michigan Press.

Roeder, P. 2007. Where Nation-States Come From: Institutional Change in the Age of Nationalism. Princeton.

Rowlands, Dane and David Carment. 1998. "Moral Hazard and Conflict Intervention." In Murray Wolfson, ed., The Political Economy of War and Peace. London, UK: Kluwer Academic Publishers.

Sakwa, Richard. 2016. Frontline Ukraine: Crisis in the Borderlands. London: I.B. Tauris.

Salehyan, Idean. 2007. "Transnational Rebels: Neighboring States as Sanctuary for Rebel Groups." World Politics 59 (2): 217-242.

Salehyan, Idean, Kristian Skrede Gleditsch, David Cunningham. 2011. "Explaining External Support for Insurgent Groups." International Organization 65 (Fall): 709-44.

Sambanis, Nicholas and Moses Shayo. 2013. "Social Identification and Ethnic Conflict." American Political Science Review 107 (2): 294-325.

Sambanis, Nicholas, Stergios Skaperdas, and William Wohlforth. 2015. "Nation-Building through War." American Political Science Review 109 (2): 279-296.

Sambanis, Nicholas, Micha Germann, and Andreas Schädel. 2015. "SDM: A new dataset on self-determination movements with an application to the reputational theory of conflict." Unpublished manuscript, University of Pennsylvania.

Sawyer, Katherine, Kathleen Gallagher Cunnningham, and William Reed. 2015. "The Role of External Support in Civil War Termination." Journal of Conflict Resolution 1-29.

Schulhofer-Wohl, Jonah. 2016. xxxx

Skaperdas, Stergios. 2006. "Bargaining versus Fighting." Defence and Peace Economics 17 (6): $657-676$.

Snidal, Duncan. 1991. "Relative Gains and the Pattern of International Cooperation." American Political Science Review 85 (3): 701-726.

Snyder, Jack L. 1993. "Nationalism and the Crisis of the Post-Soviet State. Survival 
35(1): 5-26.

Spolaore, Enrico. 2008. "Civil Conflict and Secession." Economics of Governance 9 (1): 45-63.

Sundberg, Ralph and Erik Melander. 2013. "Introducing the UCDP Georeferenced Event Dataset." Journal of Peace Research 50 (4): 523-532.

Telepneva, Natalya. 2014. "Our Sacred Duty: The Soviet Union, the Liberation Movements in the Portuguese Colonies, and the Cold War, 1961-1975." Ph.D Diss. London School of Economics.

Toukan, Mark. 2017. "International Politics by Other Means: External Sources of Civil War." Unpublished paper, University of Wisconsin.

Wagner, Harrison. 2005. "The Hazards of Thinking about Moral Hazard." Ethnopolitics 4 (2): 237-246.

Wagner, Harrison. 2007. The Theory of International Politics: War and the State. Ann Arbor: University of Michigan Press.

Westad, Odd Arne. 2006. The Global Cold War: Third World Interventions and the Making of our Times. Cambridge, Cambridge University Press.

Wilson, Andrew 2016. "The Donbas in 2014: Explaining Civil Conflict Perhaps, but not Civil War." Europe-Asia Studies 68/4 631-652.

Wimmer, Andreas. 2002. Nationalist Exclusion and Ethnic Conflict. Cambridge: Cambridge University Press.

Wimmer, Andreas and Brian Min. 2006. "From Empire to Nation-State: Explaining Wars in the Modern World, 1816-2001." American Sociological Review 71: 867-897.

Wimmer, Andreas. 2012. Waves of War: Nationalism, State Formation, and Ethnic Exclusion in the Modern World. Cambridge: Cambridge University Press.

Zhukov, Yuri. 2015. "Trading Hard Hats for Combat Helmets: The Economics of Rebellion in Eastern Ukraine." Journal of Comparative Economics 44 (1): 1-15. 


\section{Appendix}

\section{Proof of Proposition 1:}

(i) Taking the derivative of the right-hand-side of (10), we obtain:

$$
\begin{aligned}
& \frac{\partial\left\{\frac{c_{a}\left(Y+S_{b}^{*}+(1-\alpha) \Delta\right)}{c_{b} Y+c_{a}\left(Y+S_{b}^{*}+(1-\alpha) \Delta\right)}\left(S_{b}^{*}+(1-\alpha) \Delta\right)\right\}}{\partial S_{b}^{*}}=\frac{c_{a}\left(Y+S_{b}^{*}+(1-\alpha) \Delta\right)}{c_{b} Y+c_{a}\left(Y+S_{b}^{*}+(1-\alpha) \Delta\right)}+ \\
& +\left\{\frac{c_{a}}{c_{b} Y+c_{a}\left(Y+S_{b}^{*}+(1-\alpha) \Delta\right)}-\frac{c_{a}^{2}\left(Y+S_{b}^{*}+(1-\alpha) \Delta\right)}{\left[c_{b} Y+c_{a}\left(Y+S_{b}^{*}+(1-\alpha) \Delta\right)\right]^{2}}\right\}\left(S_{b}^{*}+(1-\alpha) \Delta\right)= \\
& =\frac{c_{a}\left(Y+S_{b}^{*}+(1-\alpha) \Delta\right)}{c_{b} Y+c_{a}\left(Y+S_{b}^{*}+(1-\alpha) \Delta\right)}+\frac{c_{a} c_{b} Y}{\left[c_{b} Y+c_{a}\left(Y+S_{b}^{*}+(1-\alpha) \Delta\right)\right]^{2}}\left(S_{b}^{*}+(1-\alpha) \Delta\right)>0
\end{aligned}
$$

(ii) Same steps as in (i) yield the result.

(iii) Since $F$ is the sole term on the left-hand-side of (10), the lower is $F$ the more likely is that (10) will be satisfied.

$$
\begin{aligned}
& \text { (iv) } \left.\frac{\partial\left\{\frac{c_{a}\left(Y+S_{b}^{*}+(1-\alpha) \Delta\right)}{c_{b} Y+c_{a}\left(Y+S_{b}^{*}+(1-\alpha) \Delta\right)}\left(S_{b}^{*}+(1-\alpha) \Delta\right)\right\}}{\partial c_{b}}=-\frac{c_{a}\left(Y+S_{b}^{*}+(1-\alpha) \Delta\right) Y}{\left[c_{b} Y+c_{a}\left(Y+S_{b}^{*}+(1-\alpha) \Delta\right)\right]^{2}}\left(S_{b}^{*}+(1-\alpha) \Delta\right)\right\}<0 \\
& \text { (v) } \frac{\partial\left\{\frac{c_{a}\left(Y+S_{b}^{*}+(1-\alpha) \Delta\right)}{c_{b} Y+c_{a}\left(Y+S_{b}^{*}+(1-\alpha) \Delta\right)}\left(S_{b}^{*}+(1-\alpha) \Delta\right)\right\}}{\partial c_{a}}= \\
& =\left\{\frac{\left(Y+S_{b}^{*}+(1-\alpha) \Delta\right)}{c_{b} Y+c_{a}\left(Y+S_{b}^{*}+(1-\alpha) \Delta\right)}-\frac{c_{a}\left(Y+S_{b}^{*}+(1-\alpha) \Delta\right)^{2}}{\left[c_{b} Y+c_{a}\left(Y+S_{b}^{*}+(1-\alpha) \Delta\right)\right]^{2}}\right\}\left(S_{b}^{*}+(1-\alpha) \Delta\right)= \\
& =\frac{c_{a} Y\left(Y+S_{b}^{*}+(1-\alpha) \Delta\right)}{\left[c_{b} Y+c_{a}\left(Y+S_{b}^{*}+(1-\alpha) \Delta\right)\right]^{2}}\left(S_{b}^{*}+(1-\alpha) \Delta\right)>0 \\
& (v i) \frac{\partial\left\{\frac{c_{a}\left(Y+S_{b}^{*}+(1-\alpha) \Delta\right)}{c_{b} Y+c_{a}\left(Y+S_{b}^{*}+(1-\alpha) \Delta\right)}\left(S_{b}^{*}+(1-\alpha) \Delta\right)\right\}}{\partial \alpha}=-\frac{c_{a}\left(Y+S_{b}^{*}+(1-\alpha) \Delta\right)}{c_{b} Y+c_{a}\left(Y+S_{b}^{*}+(1-\alpha) \Delta\right)} \Delta+ \\
& +\left\{\frac{-c_{a} \Delta}{c_{b} Y+c_{a}\left(Y+S_{b}^{*}+(1-\alpha) \Delta\right)}-\frac{c_{a}\left(Y+S_{b}^{*}+(1-\alpha) \Delta\right)\left(-c_{a} \Delta\right)}{\left[c_{b} Y+c_{a}\left(Y+S_{b}^{*}+(1-\alpha) \Delta\right)\right]^{2}}\right\}\left(S_{b}^{*}+(1-\alpha) \Delta\right)= \\
& \left.=-\frac{c_{a}\left(Y+S_{b}^{*}+(1-\alpha) \Delta\right)}{c_{b} Y+c_{a}\left(Y+S_{b}^{*}+(1-\alpha) \Delta\right)} \Delta-\frac{c_{a} \Delta c_{b} Y}{\left[c_{b} Y+c_{a}\left(Y+S_{b}^{*}+(1-\alpha) \Delta\right)\right]^{2}}\left(S_{b}^{*}+(1-\alpha) \Delta\right)<0 \text { (for } \alpha>1 / 2\right)
\end{aligned}
$$

(vii) The higher $\Delta$ is and the lower $\alpha$ (for $\alpha>1 / 2$ ), the higher is the polarization index $\alpha(1-\alpha) \Delta$. Therefore, by (ii) and (vi), anything that increases polarization also increases the right-hand-side of (10) and, thus, the likelihood of War.

\section{Equilibrium under Settlement}

The equilibrium choices of military efforts are determined by first taking the own derivatives of the payoff functions in (12) with respect to the own strategies of each side:

$$
\begin{aligned}
& \frac{\partial U_{a}^{s}\left(m^{s}, m^{s}\right)}{\partial m_{a}}=\frac{m_{b}^{s}}{\left(m_{a}^{s}+m_{b}^{s}\right)^{2}}\left(Y+S_{b}^{*}+(1-\alpha) \Delta\right)-c_{a}=0 \\
& \frac{\partial U_{b}^{s}\left(m^{s}, m^{s}\right)}{\partial m_{b}}=\frac{m_{a}^{s}}{\left(m_{a}^{s}+m_{b}^{s}\right)^{2}}\left(Y+S_{b}^{*}+(1-\alpha) \Delta\right)-c_{b}=0
\end{aligned}
$$


Solving this system yields the following equilibrium choices of military efforts:

$$
\begin{aligned}
& m_{a}^{s}=\frac{c_{b}\left(Y+S_{b}^{*}+(1-\alpha) \Delta\right)}{\left(c_{b}+c_{a}\right)^{2}} \\
& m_{b}^{s}=\frac{c_{a}\left(Y+S_{b}^{*}+(1-\alpha) \Delta\right)}{\left(c_{b}+c_{a}\right)^{2}}
\end{aligned}
$$

It can be shown that $m_{a}^{s}>m_{a}^{w}$ for all parameter values and $m_{b}^{s}>m_{b}^{w}$ provided that $S_{b}^{*}+$ $(1-\alpha) \Delta$ relative to $Y$ (specifically, $\left.\frac{Y+S_{b}^{*}+(1-\alpha) \Delta}{Y}>\frac{c_{b}^{2}}{c_{a}^{2}}\right)$. The associated implied probabilities of winning in the event of War (but when Settlement is the outcome) are:

$$
\begin{aligned}
p_{a}^{s} & =\frac{c_{b}}{c_{b}+c_{a}} \\
p_{b}^{s} & =1-p_{a}^{s}=\frac{c_{a}}{c_{b}+c_{a}}
\end{aligned}
$$

Unambiguously, $p_{a}^{s}>p_{a}^{w}$ and $p_{b}^{s}=1-p_{a}^{s}<1-p_{a}^{w}=p_{b}^{w}$, and the probability of winning for the rebels when War is expected (and is an equilibrium) is higher than when Settlement is expected (and is the equilibrium). Given these inequalities, and following the comparisons under which we derived (10), War cannot occur and Settlement can occur (provided there is rebellion) when $2 F \geq\left(1-p_{a}^{w}\right)\left(S_{b}^{*}+(1-\alpha) \Delta\right)>\left(1-p_{a}^{s}\right)\left(S_{b}^{*}+(1-\alpha) \Delta\right)$, whereas War becomes possible when $\left(1-p_{a}^{w}\right)\left(S_{b}^{*}+(1-\alpha) \Delta\right)>2 F>\left(1-p_{a}^{s}\right)\left(S_{b}^{*}+(1-\alpha) \Delta\right)$ or $\left(1-p_{a}^{w}\right)\left(S_{b}^{*}+(1-\alpha) \Delta\right)>\left(1-p_{a}^{s}\right)\left(S_{b}^{*}+(1-\alpha) \Delta\right) \geq 2 F$ hold.

\section{Classification of Equilibria}

For rebellion to occur, it is necessary that either $V_{b}^{w}$ or $V_{b}^{s}$ is greater than the status quo payoff $U_{b}^{q}=(1-\gamma) Y-(1-\alpha) \Delta$. Because $p_{a}^{s}>p_{a}^{w}$ it can be shown that $V_{b}^{w}>V_{b}^{s}$ always holds. Thus if it were to pay to rebel and settle (i.e., if $V_{b}^{s}>U_{b}^{q}$ ), then it would also pay to rebel and engage in War provided that (10) satisfied.

There are three types of equilibria that can occur in our model: One in which $B$ acquiesces to the status quo; another in which $B$ rebels that is followed by Settlement; and the third one in which rebellion by $B$ is followed by War. Which equilibrium occurs depends, first, on the relationship between $V_{b}^{w}, V_{b}^{s}$, and $U_{b}^{q}$ and, second, on whether inequalities such (10) 
are satisfied or not. Let $D^{i} \equiv\left(1-p_{a}^{i}\right)\left(S_{b}^{*}+(1-\alpha) \Delta\right)$, where $i=w, s$ and is the righthand sides of (6) and (10) under War and Settlement, and it provides with a short-hand in characterizing the conditions under which each of the three types of equilibrium may exist in the next Proposition. (Note that, because $p_{a}^{s}>p_{a}^{w}$, we always have $D^{w}>D^{s}$.)

Lemma: (i) If $U_{b}^{q}>V_{b}^{w}\left(>V_{b}^{s}\right)$, regardless of the relationship between $2 F$ to the $D^{i}$ s, there is a unique equilibrium that involves $B$ choosing the status quo. (ii) If $V_{b}^{w}>U_{b}^{q}$ and $D^{w}>D^{s}>2 F$, then rebellion followed by War is a possible equilibrium but rebellion followed by Settlement is not possible as an equilibrium; (iii) If ( $\left.V_{b}^{w}>\right) V_{b}^{s}>U_{b}^{q}$ and $2 F>D^{w}\left(>D^{s}\right)$ then rebellion followed by Settlement is a possible equilibrium but rebellion followed by War is not possible as an equilibrium; (iv) If $V_{b}^{w}>V_{b}^{s}>U_{b}^{q}$ and $D^{w}>2 F>D^{s}$, then both rebellion with War and rebellion with Settlement are possible equilibria. ${ }^{31}$

Part (i) of this Lemma is obvious. For part (ii), first note that for $B$ to choose rebellion with War we must have $V_{b}^{w}>U_{b}^{q}$. Second, $D^{s}>2 F$ implies that, under the military effort choices $m_{a}^{s}$ and $m_{b}^{s}$, there is no possible division of the total surplus that could avoid War and, therefore, rebellion followed by Settlement cannot be an equlibrium. Third, $D^{w}>2 F$, also implies that, under the military effort choices $m_{a}^{w}$ and $m_{b}^{w}$, Settlement is not possible but rebellion followed by War is. Thus, under the condition of part (ii) only rebellion followed by War is possible as an equilibrium. Parts (iii) and (iv) of the Lemma follow the same logic as that of part (ii).

\section{The Model When the Rebels Seek to Overthrow the Government}

This part of the appendix develops the model in which the goal of rebellion is to overthrow of the central government. The interaction is between the central government of the country that is associated with a particular group or class $A$ and a group or class, denoted by $B$, that may seek to violently overthrow the government or seek concessions and settle under the threat of a violent overthrow. The sole difference from the autonomy model is that when the government loses in the event of war, it incurs a cost of $\alpha \Delta$. To avoid pathological cases, we

\footnotetext{
${ }^{31}$ When the inequalities in this Proposition hold as equalities, then there is the possibility of multiple equilibria as well. We do not explicitly mention these cases for brevity of exposition.
} 
maintain that contesteable income $Y$ is larger than the alienation cost $\Delta$ and the expected subsidy $S_{b}^{*}$.

As with the autonomy model, the main external party that we consider is a potential sponsor of $B$, denoted by $B^{*}$, who might provide support for a rebellion and possible guarantees of economic support following a government takeover by $B$. We can also consider the effects of a potential external sponsor for the government, denoted by $A^{*}$, on the likelihood of war and rebellion as well.

The first decision that the leaders of group $B$ make is whether to choose the status quo or prepare for rebellion. Under the status quo the payoffs of the two groups are as they are under the autonomy model:

$$
\begin{aligned}
U_{a}^{q} & =\gamma Y \\
U_{b}^{q} & =(1-\gamma) Y-(1-\alpha) \Delta
\end{aligned}
$$

$B$ can prepare for a rebellion that can have three possible outcomes. In case war takes place, two possible outcomes are victory and defeat, with the probability of each outcome depending on the relative military capabilities of the insurgents and the central government of the country. Victory for the rebels would lead to government takeover whereas defeat would lead to continued rule under the central government as well as loss of material income $(1-\gamma) Y$. The third possible outcome after rebellion is for the two parties to negotiate for a settlement that takes place under the threat of war. In that case the rebels would still remain under the central government's rule but might receive a high enough share of material income so as to prevent War.

As before, letting $m_{a}$ and $m_{b}$ denote levels of military efforts incurred by the two sides, we suppose that the probabilities of the Government and the rebels winning in the event of War are:

$$
p_{a}=\frac{m_{a}}{m_{b}+m_{a}}, p_{b}=1-p_{a}=\frac{m_{b}}{m_{b}+m_{a}}
$$


The sequence of moves in case $B$ chooses the path of rebellion are as follows:

1. $A$ and $B$ choose simultaneously $m_{a}$ and $m_{b}$ military efforts.

2. A makes a Settlement offer to $B$ which consists of a division of $Y$.

3. $B$ either accepts or rejects the offer made by $A$. If they accept, the payoffs of $A$ and $B$ are in accordance with the offer. If they reject the offer, War takes place with the probabilities of winning described above.

In case of War, the expected payoffs of the two sides are:

$$
\begin{aligned}
& U_{a}^{w}=p_{a} Y+\left(1-p_{a}\right)(-\alpha \Delta)-F-c_{a} m_{a} \\
& U_{b}^{w}=p_{a}(-(1-\alpha) \Delta)+\left(1-p_{a}\right)\left(Y+S_{b}^{*}\right)-F-c_{b} m_{b}
\end{aligned}
$$

Again, the difference from the War payoffs under the autonomy model is that the Government receives a negative payoff $-\alpha \Delta$ when they lose a War.

Starting with last stage 3 of the sequence of moves described above, $B$ will have already paid its military expenditures (that is, $c_{b} m_{b}$ will have already been sunk) and therefore it will accept any share $1-\eta$ of $Y$ if and only if:

$$
(1-\eta) Y-(1-\alpha) \Delta \geq U_{b}^{w}+c_{b} m_{b}
$$

Otherwise, War will take place. Then, in stage $2 A$ would only make an offer that satisfies (21) as an equality and the resulting Settlement payoff for $A$ is at least as great as $U_{a}^{w}+c_{a} m_{a}$. That is, denoting by $\eta^{*}$ the $\eta$ that satisfies (21) as an equality, $A$ will make an offer that $B$ will accept only if

$$
\eta^{*} Y \geq U_{a}^{w}+c_{a} m_{a}
$$

But adding the two equations above, Settlement is thus possible only if

$$
2 F \geq\left(1-p_{a}\right)\left(S_{b}^{*}+(1-2 \alpha) \Delta\right)
$$


Otherwise, War will occur. Since the costs of War are positive $(F>0)$, for War to occur the right-hand-side of would have to positive and large enough. Note that the right-hand-side of (23) differs from that in (6) by having an additional negative term $-\alpha \Delta$, so that the whole term $(1-2 \alpha) \Delta$ is negative when the government represents the majority $(\alpha>1 / 2)$. This implies that with majority government it is more difficult to have War when group $B$ seeks to take over the government than when it seeks autonomy or secession. A minority government $(\alpha<1 / 2)$, however, is more vulnerable to the outbreak of War and a higher expected subsidy $S_{b}^{*}$ to the rebels could tip the rebellion into war.

We next turn to determining these probabilties by considering the equilibrium choices of military resources under War with the payoff functions under war. Taking (2) into account, the equilibrium choices, denoted by $m_{a}^{w}$ and $m_{b}^{w}$, are determined by simultaneously solving the following two derivatives of (20):

$$
\begin{aligned}
& \frac{\partial U_{a}^{w}\left(m_{a}^{w}, m_{b}^{w}\right)}{\partial m_{a}}=\frac{m_{b}^{w}}{\left(m_{a}^{w}+m_{b}^{w}\right)^{2}}(Y+\alpha \Delta)-c_{a}=0 \\
& \frac{\partial U_{b}^{w}\left(m_{a}^{w}, m_{b}^{w}\right)}{\partial m_{b}}=\frac{m_{a}^{w}}{\left(m_{a}^{w}+m_{b}^{w}\right)^{2}}\left(Y+S_{b}^{*}+(1-\alpha) \Delta\right)-c_{b}=0
\end{aligned}
$$

Note how these first-order conditions indicate that the "prize" of the war-contest for $A$ is the disputed material payoff $Y$ plus the alienation cost in the case of a loss, whereas for $B$ the prize is $Y+S_{b}^{*}+(1-\alpha) \Delta$, because $A$, by winning, does not only gain $Y$ but also gains the expected subsidy from its sponsor $\left(S_{b}^{*}\right)$ and avoids the alienation cost for its group. This is a source of asymmetry in the War contest, in addition to the other asymmetries of the model that can be expected to have an effect on the choices of military resources. Solving for $m_{a}^{w}$ and $m_{b}^{w}$ we obtain:

$$
\begin{aligned}
m_{a}^{w} & =\frac{c_{b}\left(Y+S_{b}^{*}+(1-\alpha) \Delta\right)(Y+\alpha \Delta)^{2}}{\left[c_{b}(Y+\alpha \Delta)+(1-\alpha) c_{a}\left(Y+S_{b}^{*}+(1-\alpha) \Delta\right)\right]^{2}} \\
m_{b}^{w} & =\frac{c_{a}(Y+\alpha \Delta)\left(Y+S_{b}^{*}+(1-\alpha) \Delta\right)^{2}}{\left[c_{b}(Y+\alpha \Delta)+(1-\alpha) c_{a}\left(Y+S_{b}^{*}+(1-\alpha) \Delta\right)\right]^{2}}
\end{aligned}
$$

It can be shown that the military effort of $A$ is (i) increasing in $A$ 's "prize" $Y+\alpha \Delta$; (ii) decreasing in $B^{\prime} s$ prize $Y+S_{b}^{*}+(1-\alpha) \Delta$ (iii) increasing in the opponent's marginal cost 
$c_{b}$; (iii) decreasing in own marginal cost $c_{b}$; (iv) increasing in own size $\alpha$ and decreasing in the opponent's size $1-\alpha$. The symmetric properties hold for the military efforts chosen by $B$. By substituting (25) into (19) we obain the probabilities of winning under War:

$$
\begin{aligned}
p_{a}^{w} & =\frac{c_{b}(Y+\alpha \Delta)}{c_{b}(Y+\alpha \Delta)+c_{a}\left(Y+S_{b}^{*}+(1-\alpha) \Delta\right)} \text { and } \\
p_{b}^{w} & =1-p_{a}^{w}=\frac{c_{a}\left(Y+S_{b}^{*}+(1-\alpha) \Delta\right)}{c_{b}(Y+\alpha \Delta)+c_{a}\left(Y+S_{b}^{*}+(1-\alpha) \Delta\right)}
\end{aligned}
$$

Each side's probability of winning (i) positively on own "prize" and negatively on the opponent's one; (iii) positively on own size and negative on opponent's size; and (iii) negatively on own marginal cost of military resources and positively on that of one's opponent. The higher "prize" for $B$ (due to the subsidy $S_{b}^{*}$ and avoiding the distance cost of $\Delta$ in case of a win) is thus a force counteracting the disadvantage that come from a lower size and, presumably, higher marginal cost $c_{b}$ relative to the govenrment's.

By substituting (26) into (23), we obtain that War would ensue only if the following inequality were to be satisfied:

$$
2 F<\frac{c_{a}\left(Y+S_{b}^{*}+(1-\alpha) \Delta\right)}{c_{b}(Y+\alpha \Delta)+c_{a}\left(Y+S_{b}^{*}+(1-\alpha) \Delta\right)}\left(S_{b}^{*}+(1-2 \alpha) \Delta\right)
$$

This inequality includes the combinations of solely exogenous parameter values for which War could occur. We summarize its implications as a Proposition.

Proposition A1: Conditional on B choosing to rebel, War can occur only if inequality (27) were to hold. Then War is more likely, (i) the lower is the size of the group A supporting the government and the larger is the size of group $B$ (i.e., the smaller $\alpha$ is) (ii) the higher is the external subsidy $S_{b}^{*}$;(iii) the lower is the cost of War F; (iv) the higher is group $A^{\prime} s$ marginal cost parameter $c_{a}$; $(v)$ the lower is the cost parameter $c_{b}$ of $B$ (and the more this parameter is lowered by subsidies from $B^{*}$ ); (vi) when $a<1 / 2$, the higher is the distance $\Delta$.

Proof: For brevity denote the right-hand-side of (27) by $D$. Then, the comparative static results in the Proposition follow by differentiating $D$ with respect to the variables in question. Because parts (ii) to (iv) are relatively straightforward, we derive below parts (i) and (vi) only. 
(i) $\frac{\partial D}{\partial \alpha}=\left\{\frac{-c_{a} \Delta}{c_{b}(Y+\alpha \Delta)+c_{a}\left(Y+S_{b}^{*}+(1-\alpha) \Delta\right)}-\frac{c_{a}\left(Y+S_{b}^{*}+(1-\alpha) \Delta\right)\left(c_{b} \Delta-c_{a} \Delta\right)}{\left[c_{b}(Y+\alpha \Delta)+c_{a}\left(Y+S_{b}^{*}+(1-\alpha) \Delta\right)\right]^{2}}\right\}\left(S_{b}^{*}+(1-2 \alpha) \Delta\right)-$ $2 \Delta \frac{c_{a}\left(Y+S_{b}^{*}+(1-\alpha) \Delta\right)}{c_{b}(Y+\alpha \Delta)+c_{a}\left(Y+S_{b}^{*}+(1-\alpha) \Delta\right)}$

$$
\begin{aligned}
& =-\frac{c_{a} \Delta\left[c_{b}(Y+\alpha \Delta)+c_{a}\left(Y+S_{b}^{*}+(1-\alpha) \Delta\right)\right]+c_{a}\left(Y+S_{b}^{*}+(1-\alpha) \Delta\right)\left(c_{b} \Delta-c_{a} \Delta\right)}{\left[c_{b}(Y+\alpha \Delta)+c_{a}\left(Y+S_{b}^{*}+(1-\alpha) \Delta\right)\right]^{2}}\left(S_{b}^{*}+(1-2 \alpha) \Delta\right)-2 \Delta \frac{c_{a}\left(Y+S_{b}^{*}+(1-\alpha) \Delta\right)}{c_{b}(Y+\alpha \Delta)+c_{a}\left(Y+S_{b}^{*}+(1-\alpha) \Delta\right)} \\
& =-\frac{c_{a} \Delta c_{b}\left(2 Y+S_{b}^{*}+\Delta\right)}{\left[c_{b}(Y+\alpha \Delta)+c_{a}\left(Y+S_{b}^{*}+(1-\alpha) \Delta\right)\right]^{2}}\left(S_{b}^{*}+(1-2 \alpha) \Delta\right)-2 \Delta \frac{c_{a}\left(Y+S_{b}^{*}+(1-\alpha) \Delta\right)}{c_{b}(Y+\alpha \Delta)+c_{a}\left(Y+S_{b}^{*}+(1-\alpha) \Delta\right)} \\
& =-\frac{c_{a} \Delta c_{b}\left(2 Y+S_{b}^{*}+\Delta\right)\left(S_{b}^{*}+(1-2 \alpha) \Delta\right)+2 \Delta c_{a}\left(Y+S_{b}^{*}+(1-\alpha) \Delta\right)\left[c_{b}(Y+\alpha \Delta)+c_{a}\left(Y+S_{b}^{*}+(1-\alpha) \Delta\right)\right]}{\left[c_{b}(Y+\alpha \Delta)+c_{a}\left(Y+S_{b}^{*}+(1-\alpha) \Delta\right)\right]^{2}} \\
& =-\frac{c_{a} \Delta c_{b}\left(2 Y+S_{b}^{*}+\Delta\right)\left(S_{b}^{*}+(1-2 \alpha) \Delta\right)+2 \Delta c_{a}\left(Y+S_{b}^{*}+(1-\alpha) \Delta\right) c_{b}(Y+\alpha \Delta)+2 \Delta c_{a}\left(Y+S_{b}^{*}+(1-\alpha) \Delta\right) c_{a}\left(Y+S_{b}^{*}+(1-\alpha) \Delta\right)}{\left[c_{b}(Y+\alpha \Delta)+c_{a}\left(Y+S_{b}^{*}+(1-\alpha) \Delta\right)\right]^{2}} \\
& =-\frac{c_{a} \Delta c_{b}\left[\left(2 Y+S_{b}^{*}+\Delta\right)\left(S_{b}^{*}+(1-\alpha) \Delta-\alpha \Delta\right)+2\left(Y+S_{b}^{*}+(1-\alpha) \Delta\right)(Y+\alpha \Delta)\right]+2 \Delta c_{a}\left(Y+S_{b}^{*}+(1-\alpha) \Delta\right) c_{a}\left(Y+S_{b}^{*}+(1-\alpha) \Delta\right)}{\left[c_{b}(Y+\alpha \Delta)+c_{a}\left(Y+S_{b}^{*}+(1-\alpha) \Delta\right)\right]^{2}} \\
& =-\frac{c_{a} \Delta c_{b}\left\{\left(2 Y+S_{b}^{*}+\Delta\right)\left(S_{b}^{*}+(1-\alpha) \Delta\right)-\alpha \Delta\left[\left(2 Y+S_{b}^{*}+\Delta\right)-2\left(Y+S_{b}^{*}+(1-\alpha) \Delta\right)\right]+2\left(Y+S_{b}^{*}+(1-\alpha) \Delta\right) Y\right\}}{\left[c_{b}(Y+\alpha \Delta)+c_{a}\left(Y+S_{b}^{*}+(1-\alpha) \Delta\right)\right]^{2}} \\
& -\frac{2 \Delta c_{a}\left(Y+S_{b}^{*}+(1-\alpha) \Delta\right) c_{a}\left(Y+S_{b}^{*}+(1-\alpha) \Delta\right)}{\left[c_{b}(Y+\alpha \Delta)+c_{a}\left(Y+S_{b}^{*}+(1-\alpha) \Delta\right)\right]^{2}} \\
& =-\frac{\left.c_{a} \Delta c_{b}\left[\left(2 Y+S_{b}^{*}+\Delta\right)\left(S_{b}^{*}+(1-\alpha) \Delta\right)-\alpha \Delta\left[-S_{b}^{*}-(1-\alpha) \Delta+\alpha \Delta\right)\right]+2\left(Y+S_{b}^{*}+(1-\alpha) \Delta\right) Y\right]+2 \Delta c_{a}\left(Y+S_{b}^{*}+(1-\alpha) \Delta\right) c_{a}\left(Y+S_{b}^{*}+(1-\alpha) \Delta\right)}{\left[c_{b}(Y+\alpha \Delta)+c_{a}\left(Y+S_{b}^{*}+(1-\alpha) \Delta\right)\right]^{2}} \\
& =-\frac{c_{a} \Delta c_{b}\left[\left(2 Y+S_{b}^{*}+\Delta\right)\left(S_{b}^{*}+(1-\alpha) \Delta\right)+\alpha \Delta\left[S_{b}^{*}+(1-\alpha) \Delta\right]-\alpha^{2} \Delta^{2}+2\left(Y+S_{b}^{*}+(1-\alpha) \Delta\right) Y\right]+2 \Delta c_{a}\left(Y+S_{b}^{*}+(1-\alpha) \Delta\right) c_{a}\left(Y+S_{b}^{*}+(1-\alpha) \Delta\right)}{\left[c_{b}(Y+\alpha \Delta)+c_{a}\left(Y+S_{b}^{*}+(1-\alpha) \Delta\right)\right]^{2}}
\end{aligned}
$$

Note that sole negative term in the numerator is $-\alpha^{2} \Delta^{2}$. Since $Y>\Delta$ and the term immediately next to $-\alpha^{2} \Delta^{2}, 2\left(Y+S_{b}^{*}+(1-\alpha) \Delta\right) Y>2 Y^{2}>\alpha^{2} \Delta^{2}$, the numerator of the expression is always positive. Given that the denominator is positive and the negative sign in front of the fraction, we must then have $\frac{\partial D}{\partial \alpha}<0$, as stated in the Proposition.

$$
\begin{aligned}
& \text { (vi) } \frac{\partial D}{\partial \Delta}=\frac{c_{a}\left(Y+S_{b}^{*}+(1-\alpha) \Delta\right)}{c_{b}(Y+\alpha \Delta)+c_{a}\left(Y+S_{b}^{*}+(1-\alpha) \Delta\right)}(1-2 \alpha)+\left\{\frac{c_{a}(1-\alpha)}{c_{b}(Y+\alpha \Delta)+c_{a}\left(Y+S_{b}^{*}+(1-\alpha) \Delta\right)}\right. \\
& \left.-\frac{c_{a}\left(Y+S_{b}^{*}+(1-\alpha) \Delta\right)\left(c_{a}(1-\alpha)+c_{b} \alpha\right)}{\left[c_{b}(Y+\alpha \Delta)+c_{a}\left(Y+S_{b}^{*}+(1-\alpha) \Delta\right)\right]^{2}}\right\}\left(S_{b}^{*}+(1-2 \alpha) \Delta\right) \\
& =\frac{c_{a}\left(Y+S_{b}^{*}+(1-\alpha) \Delta\right)}{c_{b}(Y+\alpha \Delta)+c_{a}\left(Y+S_{b}^{*}+(1-\alpha) \Delta\right)}(1-2 \alpha)+\left\{\frac{c_{a}(1-\alpha) c_{b}(Y+\alpha \Delta)-c_{a}\left(Y+S_{b}^{*}+(1-\alpha) \Delta\right) c_{b} \alpha}{\left[c_{b}(Y+\alpha \Delta)+c_{a}\left(Y+S_{b}^{*}+(1-\alpha) \Delta\right)\right]^{2}}\right\}\left(S_{b}^{*}+(1-2 \alpha) \Delta\right) \\
& =\frac{c_{a}\left(Y+S_{b}^{*}+(1-\alpha) \Delta\right)}{c_{b}(Y+\alpha \Delta)+c_{a}\left(Y+S_{b}^{*}+(1-\alpha) \Delta\right)}(1-2 \alpha)+\left\{\frac{c_{a}(1-\alpha) c_{b}(Y+\alpha \Delta)-c_{a}\left(Y+S_{b}^{*}+(1-\alpha) \Delta\right) c_{b} \alpha}{\left[c_{b}(Y+\alpha \Delta)+c_{a}\left(Y+S_{b}^{*}+(1-\alpha) \Delta\right)\right]^{2}}\right\}\left(S_{b}^{*}+(1-2 \alpha) \Delta\right) \\
& =\frac{c_{a}\left(Y+S_{b}^{*}+(1-\alpha) \Delta\right)}{c_{b}(Y+\alpha \Delta)+c_{a}\left(Y+S_{b}^{*}+(1-\alpha) \Delta\right)}(1-2 \alpha)+\left\{\frac{c_{a} c_{b}\left[(1-\alpha) Y+(1-\alpha) \alpha \Delta-\alpha Y-\alpha S_{b}^{*}-\alpha(1-\alpha) \Delta\right]}{\left[c_{b}(Y+\alpha \Delta)+c_{a}\left(Y+S_{b}^{*}+(1-\alpha) \Delta\right)\right]^{2}}\right\}\left(S_{b}^{*}+(1-2 \alpha) \Delta\right) \\
& =\frac{c_{a}\left(Y+S_{b}^{*}+(1-\alpha) \Delta\right)}{c_{b}(Y+\alpha \Delta)+c_{a}\left(Y+S_{b}^{*}+(1-\alpha) \Delta\right)}(1-2 \alpha)+\left\{\frac{c_{a} c_{b}\left((1-2 \alpha) Y-\alpha S_{b}^{*}\right)}{\left.\left[c_{b}(Y+\alpha \Delta)+c_{a}\left(Y+S_{b}^{*}+(1-\alpha) \Delta\right)\right]^{2}\right\}\left(S_{b}^{*}+(1-2 \alpha) \Delta\right)}\right. \\
& =\frac{c_{a} c_{b}\left(Y+S_{b}^{*}+(1-\alpha) \Delta\right)(Y+\alpha \Delta)(1-2 \alpha)+c_{a} c_{b}\left((1-2 \alpha) Y-\alpha S_{b}^{*}\right)\left(S_{b}^{*}+(1-2 \alpha) \Delta\right)+c_{a}^{2}\left(Y+S_{b}^{*}+(1-\alpha) \Delta\right)^{2}(1-2 \alpha)}{\left[c_{b}(Y+\alpha \Delta)+c_{a}\left(Y+S_{b}^{*}+(1-\alpha) \Delta\right)\right]^{2}} \\
& =\frac{c_{a} c_{b}\left[\left(Y+S_{b}^{*}+(1-\alpha) \Delta\right)(Y+\alpha \Delta)+\left((1-2 \alpha) Y-\alpha S_{b}^{*}\right) \Delta\right](1-2 \alpha)+c_{a} c_{b}\left((1-2 \alpha) Y-\alpha S_{b}^{*}\right) S_{b}^{*}+c_{a}^{2}\left(Y+S_{b}^{*}+(1-\alpha) \Delta\right)^{2}(1-2 \alpha)}{\left[c_{b}(Y+\alpha \Delta)+c_{a}\left(Y+S_{b}^{*}+(1-\alpha) \Delta\right)\right]^{2}} \\
& =\frac{c_{a} c_{b}\left[\left(Y+S_{b}^{*}+(1-\alpha) \Delta\right) Y+\alpha Y \Delta+\alpha S_{b}^{*} \Delta+(1-\alpha) \alpha \Delta^{2}+(1-2 \alpha) Y \Delta-\alpha S_{b}^{*} \Delta\right](1-2 \alpha)+c_{a} c_{b}\left((1-2 \alpha) Y-\alpha S_{b}^{*}\right) S_{b}^{*}+c_{a}^{2}\left(Y+S_{b}^{*}+(1-\alpha) \Delta\right)^{2}(1-2 \alpha)}{\left[c_{b}(Y+\alpha \Delta)+c_{a}\left(Y+S_{b}^{*}+(1-\alpha) \Delta\right)\right]^{2}} \\
& =\frac{c_{a} c_{b}\left[\left(Y+S_{b}^{*}+(1-\alpha) \Delta\right) Y+\alpha Y \Delta+(1-\alpha) \alpha \Delta^{2}+(1-2 \alpha) Y \Delta\right](1-2 \alpha)+c_{a} c_{b}\left((1-2 \alpha) Y-\alpha S_{b}^{*}\right) S_{b}^{*}+c_{a}^{2}\left(Y+S_{b}^{*}+(1-\alpha) \Delta\right)^{2}(1-2 \alpha)}{\left[c_{b}(Y+\alpha \Delta)+c_{a}\left(Y+S_{b}^{*}+(1-\alpha) \Delta\right)\right]^{2}}
\end{aligned}
$$

For $\alpha<1 / 2$, all the terms in the numerator except for $-\alpha S_{b}^{*}$ (multiplied by $c_{a} c_{b} S_{b}^{*}$ ). Since $Y>S_{b}^{*}$, we can easily find other positive terms that overwhelm that negative term. 
Given that the denominator is positive, then $\frac{\partial D}{\partial \Delta}>0$ for $a<1 / 2$ as stated in the Proposition.

Whereas the effect of the relative size of the two groups $(\alpha)$ is the same as when the rebels seek autonomy or secession, in this case the effect of the distance cost $\Delta$ is assured to hold when the government is a minority one $(\alpha<1 / 2)$. When the government is a majority one $(\alpha>1 / 2)$, the effect of $\Delta$ is ambiguous because an increase in $\Delta$ makes War ever less attractive to the government because it loses more under War.

We next consider the outcome that involves rebellion followed by Settlement. Under such an outcome, in stage 2 the Government makes an offer of $\eta^{*}(\eta$ satisfies $(21)$ as an equality) and that offer is accepted provided (23) is satisfied under the ensuing probability of winning. It can be shown that the payoff functions under such an outcome are the following:

$$
\begin{aligned}
U_{a}^{s} & =p_{a}\left(Y+S_{b}^{*}+(1-\alpha) \Delta\right)-\left(S_{b}^{*}+(1-\alpha) \Delta\right)+F-c_{a} m_{a} \\
U_{b}^{s} & =p_{a}(-(1-\alpha) \Delta)+\left(1-p_{a}\right)\left(Y+S_{b}^{*}\right)-F-c_{b} m_{b}
\end{aligned}
$$

It turns out that these two payoff functions under Settlement are the same as those under Settlement in the Autonomy model of the main text (same as in equation (12). This is true because the Government is assumed to have all the bargaining power in bargaining over Settlement which implies that the loss of $-\alpha \Delta$ if the government were to lose in the event of War (the sole difference in the two models) does not present a disadvantage in bargaining.

Therefore, the equilibrium under rebellion followed by Settlement is identical to that in the Autonomy model. Then, the equilibrium payoffs for the rebels under rebellion followed by War or by Settlement are also described by those in, respectively, (11) and (13). Consequently, inequality (14) is the one that would determine whether rebelion occurs and the results of Proposition 3 follow for the case of the rebels seeking the overthrow the government and not just, as in the main text, of the rebels seeking autonomy or secession. 
Table 1: Core Results of Montalvo \& Reynal-Querol (2005) and Extensions to Assess the Effect of the Cold War

\begin{tabular}{|c|c|c|c|c|c|}
\hline & $\begin{array}{c}1 . \\
\text { PRIOcw }\end{array}$ & $\begin{array}{c}2 . \\
\text { PRIOcw }\end{array}$ & $\begin{array}{c}3 . \\
\text { PRIOcw }\end{array}$ & $\begin{array}{c}4 . \\
\text { PRIOcw }\end{array}$ & $\begin{array}{c}5 . \\
\text { PRIOcw } \\
\text { (to 2015) }\end{array}$ \\
\hline \multirow[t]{2}{*}{ Polarization } & $2.29 *$ & $2.33^{*}$ & 1.20 & 0.81 & 1.42 \\
\hline & {$[1.06]$} & {$[1.03]$} & {$[1.17]$} & {$[1.27]$} & {$[1.10]$} \\
\hline \multirow[t]{2}{*}{ Fractionalization } & 0.18 & 0.12 & 0.16 & 0.86 & 0.06 \\
\hline & {$[0.92]$} & {$[0.92]$} & {$[0.93]$} & {$[1.14]$} & {$[0.98]$} \\
\hline \multirow[t]{2}{*}{ Cold War } & & $-0.45+$ & $-1.48 * *$ & $-1.16^{*}$ & -0.74 \\
\hline & & {$[0.25]$} & {$[0.50]$} & {$[0.58]$} & {$[0.59]$} \\
\hline \multirow[t]{2}{*}{$C W^{*} P$} & & & $1.74 *$ & $2.26^{*}$ & $1.91 *$ \\
\hline & & & {$[0.71]$} & {$[0.89]$} & {$[0.88]$} \\
\hline \multirow[t]{2}{*}{$\mathrm{CW}^{*} \mathrm{~F}$} & & & & -1.11 & -0.75 \\
\hline & & & & {$[1.00]$} & {$[0.88]$} \\
\hline $\begin{array}{l}\text { Income GDPC) } \\
\text { (LGDPC) }\end{array}$ & $\begin{array}{l}-0.42+ \\
{[0.23]}\end{array}$ & $\begin{array}{l}-0.43+ \\
{[0.24]}\end{array}$ & $\begin{array}{l}-0.44+ \\
{[0.24]}\end{array}$ & $\begin{array}{l}-0.43+ \\
{[0.24]}\end{array}$ & $\begin{array}{c}-0.62 * * \\
{[0.20]}\end{array}$ \\
\hline \multirow{2}{*}{$\begin{array}{l}\text { Population } \\
\text { (LPOP) }\end{array}$} & $0.40^{*}$ & $0.38^{*}$ & $0.38^{*}$ & $0.38^{*}$ & $0.4 * *$ \\
\hline & {$[0.18]$} & {$[0.18]$} & {$[0.18]$} & {$[0.18]$} & {$[0.14]$} \\
\hline \multirow{2}{*}{$\begin{array}{l}\text { Resource dependence } \\
\text { (PRIMEXP) }\end{array}$} & -1.07 & -1.13 & -1.15 & -1.18 & $0.88^{*}$ \\
\hline & {$[1.87]$} & {$[1.85]$} & {$[1.86]$} & {$[1.88]$} & {$[0.44]$} \\
\hline \multirow{2}{*}{$\begin{array}{l}\text { Terrain } \\
\text { (MOUNTAINS) }\end{array}$} & -0.002 & -0.002 & -0.002 & -0.002 & -0.004 \\
\hline & [0.009] & {$[0.009]$} & {$[0.009]$} & [0.009] & {$[0.008]$} \\
\hline \multirow{2}{*}{$\begin{array}{l}\text { Contiguity } \\
\text { (NONCONT) }\end{array}$} & 0.29 & 0.37 & 0.39 & 0.39 & 0.76 \\
\hline & {$[0.60]$} & {$[0.61]$} & {$[0.61]$} & {$[0.61]$} & {$[0.50]$} \\
\hline \multirow{2}{*}{$\begin{array}{l}\text { Regime type } \\
\text { (DEMOCRACY) }\end{array}$} & -0.03 & -0.05 & -0.04 & -0.02 & -0.02 \\
\hline & {$[0.37]$} & {$[0.37]$} & {$[0.37]$} & {$[0.37]$} & {$[0.02]$} \\
\hline \multirow[t]{2}{*}{ Constant } & $-6.30^{*}$ & $-5.58+$ & -4.92 & -5.12 & -1.78 \\
\hline & {$[3.14]$} & {$[3.21]$} & {$[3.21]$} & {$[3.22]$} & {$[1.86]$} \\
\hline Observations & 846 & 846 & 846 & 846 & 1225 \\
\hline Pseudo R-squared & 0.1220 & 0.1274 & 0.1312 & 0.1330 & 0.1538 \\
\hline
\end{tabular}

Robust standard errors in brackets.

NOTE: Column 5 uses different data: wars are coded until 2015 and different sources of data are used for several explanatory variables. See supplement for details. In column 5 , resource dependence is measured by a binary variable identifying countries with oil exports greater than 1/3 of GDP. Regime type of measured using the Polity index with interpolated missing values during periods of instability.

+ significant at $10 \% ; *$ significant at $5 \% ; * *$ significant at $1 \%$ 
Table 2: Effects of Intervention on Civil War Onset

\begin{tabular}{|c|c|c|c|c|c|c|}
\hline & $\begin{array}{l}\text { 1. All } \\
\text { wars }\end{array}$ & $\begin{array}{l}\text { 2. Ethnic } \\
\text { Wars }\end{array}$ & 3. All Wars & $\begin{array}{l}\text { 4. Ethnic } \\
\text { Wars }\end{array}$ & 5. All Wars & 6. Ethnic Wars \\
\hline $\begin{array}{l}\text { Pro-government } \\
\text { Intervention }\end{array}$ & $\begin{array}{r}-0.233 \\
(0.32)\end{array}$ & $\begin{array}{r}-1.347^{* *} \\
(0.56)\end{array}$ & $\begin{array}{r}-0.724 * * \\
(0.37)\end{array}$ & $\begin{array}{r}-1.099 * * \\
(0.55)\end{array}$ & $\begin{array}{r}-0.517 \\
(0.33)\end{array}$ & $\begin{array}{r}-1.604^{* *} \\
(0.63)\end{array}$ \\
\hline $\begin{array}{l}\text { Pro-rebel } \\
\text { Intervention }\end{array}$ & $\begin{array}{r}1.100 * * * \\
(0.37)\end{array}$ & $\begin{array}{r}1.536 * * * \\
(0.50)\end{array}$ & $\begin{array}{r}1.023 * * \\
(0.43)\end{array}$ & $\begin{array}{r}1.401^{* *} \\
(0.59)\end{array}$ & $\begin{array}{r}0.935 * * \\
(0.39)\end{array}$ & $\begin{array}{r}1.540 * * * \\
(0.52)\end{array}$ \\
\hline Year trend & $\begin{array}{r}- \\
0.0156^{* *} \\
(0.01)\end{array}$ & $\begin{array}{r}-0.0016 \\
(0.01)\end{array}$ & $\begin{array}{r}- \\
0.0318^{* * *} \\
(0.01)\end{array}$ & $\begin{array}{r}-0.0187 * * \\
(0.01)\end{array}$ & $\begin{array}{r}-0.0149 * * \\
(0.01)\end{array}$ & $\begin{array}{r}-0.00528 \\
(0.01)\end{array}$ \\
\hline Per capita income & & & & & $\begin{array}{r}-0.195 \\
(0.12)\end{array}$ & $\begin{array}{r}-0.144 \\
(0.12)\end{array}$ \\
\hline Population size & & & & & $\begin{array}{r}-0.0686 \\
(0.10)\end{array}$ & $\begin{array}{r}0.13 \\
(0.09)\end{array}$ \\
\hline Oil dependence & & & & & $\begin{array}{r}0.391^{*} \\
(0.22)\end{array}$ & $\begin{array}{r}0.370^{*} \\
(0.21)\end{array}$ \\
\hline Elevation difference & & & & & $\begin{array}{r}-0.028 \\
(0.25)\end{array}$ & $\begin{array}{l}0.014 \\
(0.28)\end{array}$ \\
\hline $\begin{array}{l}\text { Ethnic } \\
\text { Fractionalization }\end{array}$ & & & & & $\begin{array}{r}-0.397 \\
(0.54)\end{array}$ & $\begin{array}{r}0.14 \\
(0.41)\end{array}$ \\
\hline Religious Fractional. & & & & & $\begin{array}{r}1.344^{* *} \\
(0.65)\end{array}$ & $\begin{array}{r}2.046 * * * \\
(0.65)\end{array}$ \\
\hline $\mathrm{N}$ & 1353 & 1353 & 1261 & 978 & 1338 & 1338 \\
\hline
\end{tabular}

Standard errors in parentheses; constant omitted

$* p<.10, * * p<.05, * * * p<.01$ 


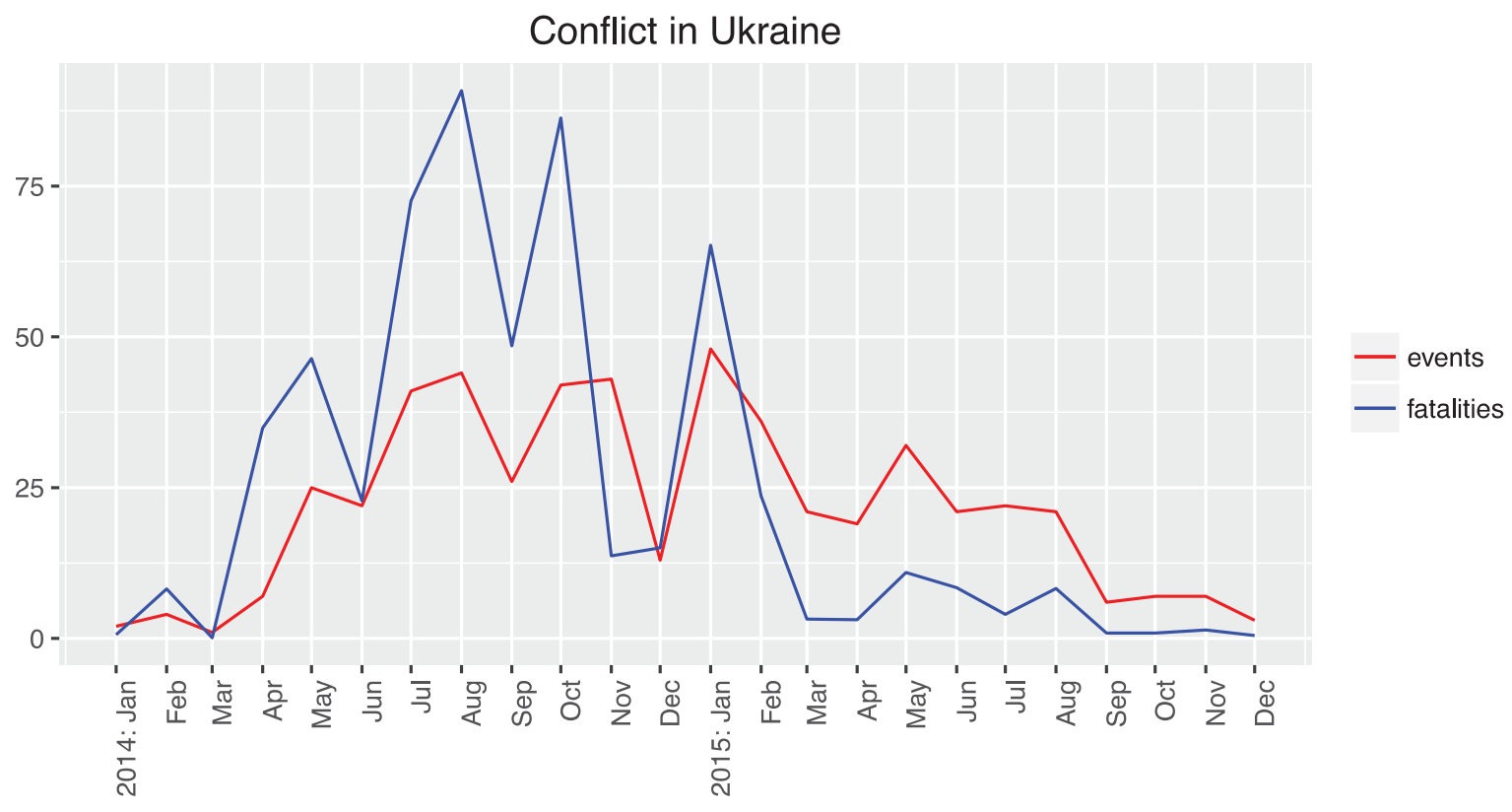

Figure 1: Conflict Events and Fatalities in Ukraine Source: UCDP 